DIVISION OF THE HUMANITIES AND SOCIAL SCIENCES

CALIFORNIA INSTITUTE OF TECHNOLOGY

PASADENA, CALIFORNIA 91125

CONTESTABLE LEADERSHIPS: PARTY DISCIPLINE AND VOTE BUYING IN LEGISLATURES

Matias laryczower

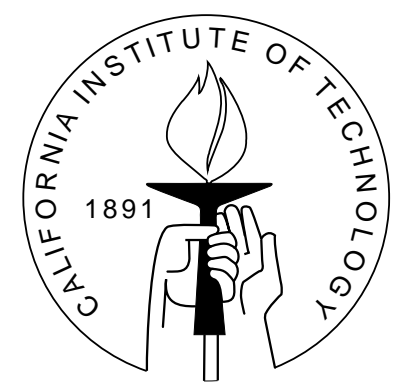

SOCIAL SCIENCE WORKING PAPER 1255

August 2006 


\title{
Contestable Leaderships: Party Discipline and Vote Buying in Legislatures
}

\author{
Matias Iaryczower
}

\begin{abstract}
This paper examines the institutional determinants of discipline in legislative parties building on the premise that leaders need to maintain support within the organization to continue leading. Payments distributed by the incumbent on the spot increase the value of promises of future benefits by fostering individuals' perceived chances that the incumbent will retain her position. The main result of the paper shows, in fact, that the party leader can use promises of future benefits to induce members to vote for a position disliked by the majority of the party only if she also distributes benefits on the spot.
\end{abstract}

JEL classification numbers: D72, D78, C72

Key words: political parties, party discipline, leadership, vote buying, pork 


\title{
Contestable Leaderships: Party Discipline and Vote Buying in Legislatures*
}

\begin{abstract}
Matias Iaryczower ${ }^{\dagger}$
“... as soon as Chamberlain had lost the confidence of a sizeable proportion of his followers in the Commons his powers as Leader of the Party (which seem on paper so impressive) were of no great importance. The vast powers of the Leader of the Conservative Party are exercised only with the consent of his followers ... However powerful he may be while he enjoys the confidence of his followers his authority evaporates the moment he loses that confidence." (McKenzie (1964))
\end{abstract}

\section{Introduction}

One of the central questions in the study of representative democracy is how partisan organizations shape decision-making in legislatures. When party discipline is strong, legislators of the same party behave cohesively, even in spite of significant internal dissent. ${ }^{1}$ Disciplined parties can therefore significantly alter the aggregation rule by which legislators' and citizens' preferences are transformed into policy outcomes. Under what conditions will a party leader be able to induce legislators of her party to support the party line, even against their preferences? When will party leaders have to yield, instead, to the views of a majority of the party? In this paper, I build on a simple but general observation about organizations - and parties in particular - to answer these questions. While leaders are endowed with resources with which to influence legislators' voting behavior, their control of the leadership is always a conditional one: leaders need to maintain a minimum level of support to continue leading (McKenzie (1964),

*I am very grateful to David Levine, Andy Atkeson, Hal Cole, Christian Hellwig, Leeat Yariv and Juliana Bambaci for helpful discussions and suggestions. I am also thankful to numerous seminar participants at Caltech, Chicago, Illinois at Urbana-Champaign, Maryland, U. Penn, Princeton, Rice, Stanford, UC Berkeley, UCSD, and Washington University in St. Louis, as well as to many others at UCLA, for useful comments to previous versions of this paper.

${ }^{\dagger}$ Division of Humanities and Social Sciences, California Institute of Technology, Pasadena, California 91125, USA, email: miaryc@hss.caltech.edu

${ }^{1}$ See Krehbiel (1993), Cox and McCubbins (1993) and Tsebelis (1995). 
Jones (1968), Sinclair (1983), Calvert (1987), Panebianco (1988), Cox and McCubbins (2005b), Myerson (2005)). ${ }^{2}$

This paper formalizes the tradeoff between resources at the leader's discretion and the contestable nature of the leadership position in the context of a heterogeneous group of party backbenchers (PBs) who are uncertain about the distribution of fellow party members preferences in a policy space. I model the internal constraints faced by the incumbent party leader as the partisan equivalent of a confidence vote procedure: the party leader is overthrown whenever her advocated position does not gather the support of a minimum proportion of party backbenchers in the legislature. I distinguish between payments that can be distributed on the spot to both members of the party and the opposition (pork) and promises of future partisan benefits, such as nomination to party lists. Introducing this distinction allows me to reevaluate the conventional wisdom in political science that "leaders who possess this power [nomination control] should be able to discipline their followers" (Morgenstern (2004)). ${ }^{3}$ It also allows me to study the interactions between spot payments and (promises of) future payments: will weak or strong parties use legislative "grease" build cross party coalitions?

The key effect of a leadership replacement in the model is its effect on the allocation of promises of future benefits, which as opposed to spot payments can only be delivered if the incumbent leader retains the command of the party. The central theme that unifies the results of the paper follows directly from this fact. Since promises are conditional on the stability of the leader, their value is not exogenously given, but instead endogenously determined by backbenchers' beliefs about the extent of support to the incumbent among other party legislators. How these beliefs are formed determines how the collective action problem among PBs opposing the incumbent is resolved, and thus ultimately how powerful the leader is vis a vis the collective principal. Discipline will also be affected by the nature and amount of resources available to the leaders, but the impact of these various instruments will be filtered by how each of them contributes to backbenchers' expectations about the incumbent's survival.

The first result shows that promises of future benefits are not well suited for this task, and can therefore be completely ineffective to provide discipline in legislative parties. It is enough for this that two conditions hold: the incumbent leader (a) has no resources to distribute on the spot and (b) can be overthrown by a rebellion of a majority of the party. Proposition 2 shows that under these conditions influence follows, in effect, from the bottom up: promises are useful (and used) only if ex ante a majority of the party agrees with the incumbent leader on the ranking of alternatives in the first place. This result complements the conventional wisdom prevailing in the discipline regarding the impact of nomination power on party discipline. The general moral is that promises of

\footnotetext{
${ }^{2}$ Party leaders do in fact fall. The resignation of Gerhard Schroeder as chairman of the Social Democratic Party (Germany) in February 2004 provides one of the latest well known examples.

${ }^{3}$ Similar assertions are widespread across the literature. Schattschneider (1942) (cited in Morgenstern (2004)) puts it even more bluntly: "The nature of the nominating procedure determines the nature of the party; he who can make the nominations is the owner of the party."
} 
future benefits will be relevant to alter voting behavior only if party members believe that the incumbent leader has a strong hold to the reins of power. With no resources to distribute on the spot, the leadership of a majoritarian institution is only conditionally stable, and the leader merely an agent of the majority of the party.

That the leader does have any influence under these conditions is entirely due to the heterogeneity of preferences within the party. While the leader is powerless without the support of the majority of the party, when she does have the ex ante support of a majority of the party the leader can exploit the possibility of internal conflict to bolster the support for the party line. As the homogeneity of backbenchers' preferences (and therefore the possibility of conflict) decreases, however, the leader's influence decreases as well, and party discipline vanishes as the heterogeneity of party members' ideal policies goes to zero: in the limit as PBs are almost perfectly homogeneous, a leader that needs the support of a majority of the party is powerless against the collective principal (proposition 3).

The negative relationship between discipline and the homogeneity of the group's preferences still holds when the leader is endowed with resources to distribute on the spot (proposition 5). Introducing spot payments, however, breaks the exact correspondence between majority support and influence of promises of future benefits. If endowed with sufficiently large amount of spot payments, the incumbent can make promises of future benefits valuable even when ex ante a majority of the party opposes the party line. To do so, however, the incumbent needs in fact to buy the party. As a result, the influence of backbenchers is lost, but rather reshaped in terms of a lower bound of payments that needs to be allocated to party members for party resources to be in play.

The previous result highlights the fact that (opposite to disputable resources such as promises of future benefits) spot payments are highly effective in this environment. In addition to their direct effect on PBs' behavior, spot payments increase the value of promises of future partisan benefits through their impact on the beliefs about the leader's survival. Keeping PBs' beliefs about the actions of fellow party members fixed, an increase of one dollar in the allocation of pork to party members increases the net value of the incumbent's offer by the same amount. Beliefs about the actions of other PBs will not remain fixed, however, as the revised offer will induce PBs to anticipate a higher support to the party line among party members, and thus a higher probability of the incumbent's survival, leading ultimately to a higher expected value of her promises.

The magnitude of the complementarity between spot payments and the value of promises of future benefits is a key determinant of the net benefit of allocating these payments to the party or the opposition. While pork can be used to attain the support of opposition legislators, this allocation has an opportunity cost: buying the opposition implies weakening the support inside the party. The magnitude of this opportunity cost will be determined, in fact, by the strength of the complementarity between spot payments and the value of promises of future benefits. Proposition 4 exploits the fact that the multiplier effect of current resources is higher the more exposed the incumbent is to internal threats, to conclude that more vulnerable leaders will allocate a higher 
proportion of pork to buy members of their own party vis-a-vis the opposition.

The remainder of the paper is organized as follows. The basic model is presented in section 2. Section 3 characterizes a symmetric, pure equilibrium employing cutoff strategies, and provides sufficient conditions for this equilibrium to be unique. ${ }^{4}$ Section 4 develops the substantive results. Section 5 extends the model to include an endogenous determination of the challenge to the incumbent leader. I show here that the basic model is a stylized description of this extended framework, assuming that policy alternatives are not "too close" in the policy space. Section 6 relates the framework and results with the literature, and Section 7 concludes. All proofs are in the Appendix.

\section{The Basic Model}

There are three types of agents in the model: (i) a party leader, (ii) a continuum of party backbenchers (PBs), with total size 1 and (iii) a continuum of size $\beta<1$ of opposition legislators. PBs and opposition legislators compose a legislature, which chooses between two given policy alternatives $q$ and $x$ in $\mathbb{R}, q<x$, by simple majority voting. ${ }^{5}$

\section{Legislators' Preferences \& Information.}

PBs face a tradeoff between pleasing their constituencies and the party leadership, two "masters" with (generically) different objectives. Their payoffs are thus determined by (i) "monetary" benefits they can extract from the party leadership, and (ii) the distance between their constituents "ideal policy" $\theta_{i}$ and the policy they voted for in the legislature, $x_{i} \in\{q, x\}$. In particular, monetary transfers enter linearly into their utility function, and policy preferences of PB $i$ are represented by a utility function $u\left(\left|x_{i}-\theta_{i}\right|\right)$. It will be convenient to define - taking the pair $(q, x)$ of policy alternatives as given - the function $v\left(\theta_{i}\right) \equiv u\left(\left|q-\theta_{i}\right|\right)-u\left(\left|x-\theta_{i}\right|\right)$. The value $v\left(\theta_{i}\right)$ denotes the net gain of voting for $q$ instead of $x$ for PB $i$, with ideal policy $\theta_{i}$. Note that by construction $v\left(\theta_{i}\right)=0$ at $\theta_{i}=\frac{x+q}{2}$, and that $|v(\cdot)|$ is symmetric around this point. Moreover, I will assume throughout that $v(\cdot)$ is a continuous function satisfying the following condition:

Assumption (A1). There exists $\underline{\alpha}>0$ such that for all $\left(\theta_{i}, \theta_{i}^{\prime}\right)$ with $\theta_{i}^{\prime}>\theta_{i}$,

$$
v\left(\theta_{i}\right)-v\left(\theta_{i}^{\prime}\right) \geq \underline{\alpha}\left(\theta_{i}^{\prime}-\theta_{i}\right)
$$

\footnotetext{
${ }^{4}$ Since opposing the incumbent leader can only be profitable if the size of the rebellion is big enough to alter the incumbent's proposed allocation of partisan benefits, PBs' choices are strategic complements. In this setting, assuming common knowledge of preferences yields multiple equilibria, sustained by self fulfilling beliefs. Relaxing this assumption, however, allows us to pin down a unique equilibrium. The argument for uniqueness follows Morris and Shin $(1998,2001,2003)$ and Frankel et al. (2001).

${ }^{5}$ With fixed alternatives, we can as well take our policy space to be $\mathbb{R}^{n}$. Similarly, as it will be apparent soon, nothing here depends on the voting rule being simple majority.
} 
The ideal policy of each $\mathrm{PB}, \theta_{i}$, is private information, but correlated with that of the other PBs. ${ }^{6}$ Specifically, I assume that the ideal policy of PB i is given by $\theta_{i}=\theta+\varepsilon_{i}$, where the common component $\theta$ is drawn from a $N\left(\theta_{0}, \eta^{2}\right)$ distribution, the idiosyncratic component $\varepsilon_{i}$ is i.i.d., and drawn from a $N\left(0, \sigma^{2}\right)$ distribution, and both $\theta$ and $\varepsilon_{i}$ are unobservable. Intuitively, a Democrat from California can observe the preferences of his constituency, but is not able to disentangle which part is due to them being californian and which part is due to them being democrats. Note then that PBs are uncertain about the distribution of their fellow party members in the policy space, and that they will be able to use their private information to reduce this uncertainty. Opposition legislators have policy preferences $u(\cdot)$ identical to those of PBs. Although their ideal policies are private information, I assume that they are distributed according to a known c.d.f. $G(\cdot)$. This implies, in particular, that the proportion of opposition legislators with ideal policy below some number $z$ is public information. ${ }^{7}$

\section{Party Leadership \& Payments}

The party leader cares about the policy outcome: the leader obtains net benefit $w>0$ from the policy outcome being $x$ instead of $q$. The leader is endowed with two types of resources with which to influence legislators' voting behavior: (i) spot payments (or pork) that can be distributed to both $\mathrm{PBs}(r)$ and opposition legislators $\left(r_{o}\right)$, and (ii) promises of future partisan benefits $(e)$ that can only be distributed to PBs. As the notation suggests, I will restrict to payments that are symmetric among legislators of the same party. Moreover, I will only allow payments to an individual to be conditional on his actions, thus precluding more complex mechanisms that could possibly depend on aggregate voting patterns. The result is the simplest possible model that allows us to focus on $(i)$ the leader's decision of whether to attempt to actively influence the party and $(i i)$ backbenchers' collective action problem of whether to follow or rebel against the leader, in an environment that is sufficiently rich so as to incorporate the key elements pinning down the resolution of party discipline. ${ }^{8}$

Spot payments are conditional offers: a PB receives $r$ when voting in favor of $x$, and zero otherwise. Similarly, an opposition legislator receives $r_{o}$ when voting in favor of $x$, and zero otherwise. The party leader chooses $r$ and $r_{o}$ subject to the (ex ante) budget constraint $r_{o} \beta+r \leq R$, where $R$ denotes the total amount of pork resources available to the leader. Residuals from unaccepted offers are kept by the incumbent leader. Unlike pork - the allocation of which is final and irreversible - conditional promises of partisan benefits can only be delivered if the incumbent leader survives internal challenges to her authority. Specifically, I assume that the party leader can choose between two alternative procedures, which I call a partisan and a non-partisan vote.

\footnotetext{
${ }^{6}$ With minor modifications, we could assume that the preferences of a fraction of "partisan" PBs are public information, and carry out the analysis with respect to the fraction of "moderate" PBs.

${ }^{7}$ The relevant assumption here is that there are no leadership challenges in the opposition.

${ }^{8}$ For an otherwise richer (asides the endogeneity of promises of future benefits) model of vote buying, see Dekel et al. (2004). For other important contributions, see Snyder (1991), Groseclose and Snyder (1996), Diermeier and Myerson (1999), Myerson (1993) and Lizzeri and Persico (2001).
} 
In a non-partisan vote the incumbent commits to distribute $e$ to every PB irrespective of his vote. Promises of future partisan benefits thus play no role in influencing the voting behavior of PBs. Moreover, in the basic model, I assume that this unconditional allocation of partisan benefits is never challenged. The net payoff of voting for $x$ for PB $i$ in a non-partisan vote is then given by $\Pi_{n p}\left(\theta_{i}\right)=r-v\left(\theta_{i}\right)$. In a party vote, instead, the incumbent commits to distribute $e$ only to PBs voting for $x$, and zero to others. I will assume, however, that the conditional allocation of partisan benefits implicit in the party vote will always trigger a challenge to the party leader. ${ }^{9}$ A challenge consists of an alternative conditional distribution of partisan benefits: if a challenge is successful, PBs voting for $q$ receive electoral benefits $e$, and those voting for $x$ receive zero. ${ }^{10}$ A challenge is successful if the incumbent's advocated position does not gather sufficient support by PBs in the legislature; i.e., if the mass of PBs in the incumbent's coalition, denoted by $\Gamma$, does not reach a minimum threshold $\mu(\mu \leq 1 / 2)$. To summarize, the net monetary payoff for a $\mathrm{PB}$ voting for $x$ is $e$ if the incumbent survives the challenge (if $\Gamma<\mu$ ), and $-e$ if the incumbent is overthrown. The net expected payoff of voting for $x$ for $\mathrm{PB} i$ in a party vote is then $\Pi_{p}\left(\theta_{i}\right)=r+e\left[1-2 \operatorname{Pr}\left(\Gamma<\mu \mid \theta_{i}\right)\right]-v\left(\theta_{i}\right)$

\section{Strategies and Equilibrium}

Taking advantage of my minimalist representation of opposition legislators, I will exclude them from the set of players, and instead consider their best responses as part of the environment. Specifically, since the pork resource constraint $r_{o} \beta+r \leq R$ will hold with equality at the optimum, we substitute $r_{o}=\frac{R-r}{\beta}$, and treat the main party leader's allocation decision simply as a choice of a pork offer to party members $r \in[0, R]$. Given any such offer $r$, the mass of legislators in the opposition voting for $x$ is then given by $\left[1-G\left(v^{-1}\left(\frac{R-r}{\beta}\right)\right)\right] \beta$. The players in the modified game are therefore PBs and the incumbent party leader.

The timeline consists of three stages. In Stage 1, nature chooses a realization of the unobservable random variables $\theta$ and $\left\{\varepsilon_{i}\right\}$, and each $\mathrm{PB} i$ privately observes his ideal policy $\theta_{i}=\theta+\varepsilon_{i}$. The party leader receives no such private signal. In Stage 2 , the party leader decides (i) whether to make the vote a non-partisan vote or a party vote, and (ii) an allocation of pork to PBs. In Stage 3, legislators vote between the alternatives $x$ and $q$.

A strategy for the incumbent leader is therefore a choice of a couple $\left(a_{I}, r\right)$, where $a_{I} \in\{n p, p\}$ and $r \in[0, R]$. The incumbent's choice of $a_{I}$ induces, respectively, a nonpartisan-voting game and a party-voting game among PBs. A strategy for a $\mathrm{PB} i$ can

\footnotetext{
${ }^{9}$ Section 5 extends the model allowing an endogenous determination of the challenge. There we show that the incumbent won't be challenged (i) in a non-partisan vote or (ii) in a party vote if $x$ is sufficiently close to $q(x<\widetilde{x}$ for some $\widetilde{x})$, but is challenged whenever $x>\widetilde{x}$. The basic model is thus a reduced form of the complete model, assuming that alternatives are not "too close" in the policy space.

${ }^{10}$ As with pork, due to unaccepted offers, in a party vote there won't be ex post budget balance of electoral benefits. The remainder can be assumed to be distributed to party members who are not currently in Congress, or kept in the leader's safe box.
} 
therefore be described by a pair of functions $\varkappa_{i}^{n p}(\cdot ; r)$ and $\varkappa_{i}^{p}(\cdot ; r)$ mapping the set of types $\Theta$ and possible pork allocations to party members $[0, R]$ to $\{q, x\}$. The resulting $\varkappa_{i}^{n p}\left(\theta_{i} ; r\right)$ and $\varkappa_{i}^{p}\left(\theta_{i} ; r\right)$ are therefore the votes of a PB $i$ with ideal policy $\theta_{i}$ in the non-partisan-voting and party-voting games, given an offer of pork $r$ to party members. An equilibrium is a strategy profile $\left(\left(a_{I}, r\right),\left\{\varkappa_{i}^{n p}(\cdot ; r), \varkappa_{i}^{p}(\cdot ; r)\right\}_{i}\right)$ such that $(i)\left(a_{I}, r\right)$ is feasible and sequentially rational and that $(i i)\left\{\varkappa_{i}^{n p}(\cdot ; r)\right\}_{i}$ and $\left\{\varkappa_{i}^{p}(\cdot ; r)\right\}_{i}$ constitute, respectively, a BNE of the non-partisan-voting and party-voting games.

\section{The Fundamentals: Voting}

After characterizing equilibria in non-partisan voting (Remark 1), I turn to the core of the section: the analysis of party votes. I show that if the distribution of PBs' preferences is common knowledge, radically different behavioral patterns can be sustained as equilibria of party votes by self-fulfilling beliefs (Remark 2). Relaxing this assumption allows us to pin down a unique equilibrium, which I characterize in Proposition 1.

Consider first non-partisan voting. Note that the net payoff of voting for $x$ for a PB $i$ is here given by $\Pi_{n p}\left(\theta_{i}\right)=r-v\left(\theta_{i}\right)$, and is therefore independent of the actions of other players (this is a decision problem). Letting $\delta_{n p}(r) \equiv v^{-1}(r)$, we then have

Remark 1 (Non-Partisan Voting) In a non-partisan voting equilibrium, $\varkappa_{i}^{n p}\left(\theta_{i} ; r\right)=$ $x$ for all $i$ such that $\theta_{i}>\delta_{n p}(r)$ and $\varkappa_{i}^{n p}\left(\theta_{i} ; r\right)=q$ for all $i$ such that $\theta_{i}<\delta_{n p}(r)$

The situation is qualitatively different in a party vote. In a party vote, only PBs with "extreme" policy preferences are impervious to the actions of fellow party members. The decision of "centrist" individuals, instead, is determined by their beliefs about what others will do. For these individuals, supporting the incumbent's party line is optimal only if doing so allows them to capture a sufficiently high level of expected party payments. The net expected value of the incumbent's offer for individual $i$ depends, in turn, on whether the incumbent leader will be able to retain the command of the party, and thus on $i$ 's beliefs about the proportion of PBs supporting the incumbent's party line. If $i$ believes that more than $\mu$ PBs will stick with the incumbent leader, he will want to do so as well; if he believes that at least $1-\mu$ PBs will defect, he will "defect" too.

In particular, if the distribution of party members' preferences is common knowledge, and the proportion of "extremists" is not high enough to determine the outcome of the incumbent's survival from the outset, radically different behavioral patterns can be sustained as equilibria by self-fulfilling beliefs. ${ }^{11}$

\footnotetext{
${ }^{11}$ When $\theta+\sigma \Phi^{-1}(1-\mu)<\theta_{i}$, strategy profile (1) in the remark constitutes the unique BNE of the party vote game. Similarly, when $\theta+\sigma \Phi^{-1}(1-\mu)>\overline{\theta_{i}}$, strategy profile $(2)$ is the unique BNE.
} 
Remark 2 Let $\underline{\theta_{i}} \equiv v^{-1}(r+e)$ and $\overline{\theta_{i}} \equiv v^{-1}(r-e)$. Suppose that $\theta$ is common knowledge, and that $\theta_{i}<\theta+\sigma \Phi^{-1}(1-\mu)<\overline{\theta_{i}}$. Then the following strategy profiles are $B N E$ of the party voting game:

(1) $\varkappa_{i}^{p}\left(\theta_{i} ; r\right)=x \forall i: \theta_{i}>\underline{\theta_{i}}$ and $\varkappa_{i}^{p}\left(\theta_{i} ; r\right)=q \quad \forall i: \theta_{i}<\underline{\theta_{i}}$ and

(2) $\varkappa_{i}^{p}\left(\theta_{i} ; r\right)=x \forall i: \theta_{i}>\overline{\theta_{i}}$ and $\varkappa_{i}^{p}\left(\theta_{i} ; r\right)=q \forall i: \theta_{i}<\overline{\theta_{i}}$

Proof. All proofs are in the appendix.

The assumption that the distribution of party members' preferences is common knowledge among PBs, however, is not desirable per se. Moreover, as recent developments in the global games literature show, relaxing this assumption allows us to pin down a unique equilibrium (see Morris and Shin $(1998,2001,2003)$ and Frankel et al. (2001). The basic results are summarized in proposition 1 below: when PBs are uncertain about the central tendency of the party (i) there exists a symmetric equilibrium in which PBs employ switching strategies with a cutpoint $\delta_{p} \in\left(\underline{\theta_{i}}, \overline{\theta_{i}}\right)$. Moreover, (ii) this equilibrium is unique provided that the uncertainty about the central tendency of the party (as parameterized by $\eta$ ) is high enough. The cutpoint $\delta_{p}$, which completely characterizes this equilibrium, is pinned down by the net expected value attached by the critical player with ideal policy $\delta_{p}$ to the promises of electoral benefits made by the incumbent leader.

\subsection{Uniqueness of Equilibrium in Party Votes}

Consider a symmetric strategy profile in which PBs employ switching strategies with an arbitrary cutpoint $\delta$. Denote by $\Pi\left(\theta_{i} ; \delta\right)$ the net expected benefit of supporting $x$ for a PB with ideal policy $\theta_{i}$ given this strategy profile. Similarly, denote by $\Gamma(\theta, \delta)$ the proportion of PBs voting for $x$ according to this strategy profile given a particular realization of $\theta$. Since $\theta_{i} \mid \theta \sim N\left(\theta, \sigma^{2}\right)$, then $\Gamma(\theta, \delta)=1-\Phi\left(\frac{\delta-\theta}{\sigma}\right)$, where $\Phi(\cdot)$ is the c.d.f. of the standard normal. Hence $\Gamma(\theta, \delta)=1-\Phi\left(\frac{\delta-\theta}{\sigma}\right)<\mu \Longleftrightarrow \theta<\delta-\sigma \Phi^{-1}(1-\mu)$, so that

$$
\Pi\left(\theta_{i} ; \delta\right)=r+e\left[1-2 \operatorname{Pr}\left(\theta<\delta-\sigma \Phi^{-1}(1-\mu) \mid \theta_{i}\right)\right]-v\left(\theta_{i}\right)
$$

By Bayes' Law, $\theta \mid \theta_{i} \sim N\left(\widehat{\theta}\left(\theta_{i}\right), \widehat{\eta}^{2}\right)$, where $\widehat{\theta}\left(\theta_{i}\right) \equiv \frac{\sigma^{2} \theta_{0}+\eta^{2} \theta_{i}}{\sigma^{2}+\eta^{2}}$ and $\widehat{\eta} \equiv \frac{\sigma \eta}{\sqrt{\sigma^{2}+\eta^{2}}}$. I then define the function

$$
P\left(\delta, \theta_{i}\right) \equiv 1-2 \Phi\left(\left(\frac{\theta-\widehat{\theta}\left(\theta_{i}\right)}{\widehat{\eta}}\right)_{\theta=\delta-\sigma \Phi^{-1}(1-\mu)}\right)
$$


Intuitively, $P\left(\delta, \theta_{i}\right)$ is the net expected value of a dollar of electoral benefits made conditional on supporting the incumbent leader's party line for an individual with ideal policy $\theta_{i}$, when every PB uses a switching strategy with cutoff point $\delta$. Then:

$$
\Pi\left(\theta_{i} ; \delta\right)=r+e P\left(\delta, \theta_{i}\right)-v\left(\theta_{i}\right)
$$

Denoting by $p(\delta) \equiv P(\delta, \delta)$ the net expected value of a dollar of electoral benefits for the critical $P B$ with ideal policy $\delta$, and letting $\pi(\delta) \equiv \Pi(\delta ; \delta)$, we have

$$
\pi(\delta)=r+e p(\delta)-v(\delta)
$$

Lemma 3 in the appendix shows that $(i) p(\cdot)$ is a decreasing function, and that $(i i)\left|p^{\prime}(\cdot)\right|$ is bounded above by a decreasing function of $\eta$ which goes to zero as $\eta \rightarrow \infty$. To grasp the intuition for the first result, note that this is equivalent to saying that a more "rightwinged" critical PB assigns a higher probability to the incumbent being overthrown. Since the cdf of $\theta$ conditional on $\theta_{i}$ is stochastically increasing in $\theta_{i}$, an increase in $\delta$ not only (i) increases the cutoff point determining whether other PBs will support or challenge the incumbent (vote for $x$ or $q$ ), but also (ii) changes the beliefs of the critical PB concerning the central tendency of the party: a more right-winged critical PB will consider less likely that the incumbent will be overthrown. As the effect of $\delta$ on beliefs is dampened by the priors, however, the first effect dominates, producing the result. ${ }^{12}$ Since by A1 the slope of $v(\cdot)$ is bounded away from zero, this implies that for sufficiently high $\eta, \pi(\cdot)$ is an increasing function and $\pi(\delta)=0$ at exactly one point.

[Figure 1]

Proposition 1 is then a rather straightforward application of similar results in the global games literature (see Morris and Shin (1998, 2001, 2003), and Frankel et al. (2001)):

Proposition 1 Let $\delta_{p} \in\{\delta: \pi(\delta)=0\} \neq \varnothing$. There exists a symmetric equilibrium of the party vote game in which $\varkappa_{i}^{p}\left(\theta_{i}, r\right)=x$ for all $i$ such that $\theta_{i} \geq \delta_{p}$ and $\varkappa_{i}^{p}\left(\theta_{i}, r\right)=q$ for all $i$ such that $\theta_{i}<\delta_{p}$. Moreover, there exists a $\bar{\eta}$ such that whenever $\eta>\bar{\eta},\{\delta: \pi(\delta)=0\}$ has a single element $\delta_{p}$, and this equilibrium is unique.

\footnotetext{
${ }^{12}$ The second result follows from the same logic, since increasing $\eta$ diffuses the prior, and thus diminishes the "dampening" of the change in beliefs.
} 


\section{Party Discipline and Vote Buying}

In this section, I turn to the substantive analysis leading to the main conclusions of the paper. In doing so, I assume throughout that the condition in proposition 1 is met. I start by making precise the definition of party discipline that I will employ in the remainder of the paper.

\subsection{Party Discipline: A Definition}

The informal definition of party discipline advanced in the introduction referred to the ability of party leaders to influence the voting behavior of PBs with partisan resources. This brief section has the double purpose of providing a rationale for this definition, and of making it more precise. The definition I will employ is as follows:

Definition 1 Define party discipline, $d:[0, R] \rightarrow \mathbb{R}$, by

$$
d(r) \equiv \inf \left\{\theta_{i}: \varkappa_{i}^{n p}\left(\theta_{i} ; r\right)=x\right\}-\inf \left\{\theta_{i}: \varkappa_{i}^{p}\left(\theta_{i} ; r\right)=x\right\}=\delta_{n p}-\delta_{p}
$$

That is, given an allocation $r$ of pork to party members, I define party discipline as the difference between the ideal policy of the most left-winged PB supporting the incumbent's party line in a non-partisan vote, and that of the most left-winged PB supporting the party line in a party vote. By remark 1 and proposition 1, then, it follows that (i) $d(r)=\delta_{n p}-\delta_{p}$, and (ii) $d(r)>0 \Leftrightarrow p\left(\delta_{p}\right)>0$. Point (ii) simply notes that discipline is positive if and only if the critical $\mathrm{PB} \delta_{p}$ assigns positive (net) value to the promises of future partisan benefits offered by the incumbent leader.

This definition satisfies several appealing properties. First, a useful definition of party discipline must distinguish between the non-partisan and the partisan frameworks. Specifically, party discipline should not reflect unity in voting that is driven by the absence of conflict between PBs over their preferred alternative. Instead, party discipline must indicate the ability of the party, and in particular of the party leadership, to mold PBs' behavior. Krehbiel (1993) makes the point sharply: "[D]o legislators vote with fellow party members in spite of their disagreement about the policy in question, or ... because of their agreement about the policy in question." ${ }^{13}$ The comparison of the partisan and non-partisan thresholds $\delta_{p}$ and $\delta_{n p}$ accomplishes this demand without being (directly) influenced by the distribution of preferences within the party (e.g., heterogeneity of PBs' preferences, $\sigma$ ). This measurement of discipline, moreover, is largely consistent with that employed in recent empirical studies of voting in the US Congress (Snyder and Groseclose (2000), McCarty et al. (2001), Cox and Poole (2002)). As a result of this, the theoretical

\footnotetext{
${ }^{13}$ In the same vein, Cox and McCubbins (1993) argue that " [I]nvestigations of parties as floor voting coalitions ought to be conducted in terms of loyalty to party leaders and not, as has usually been done in the previous literature, in terms of general party cohesion." Similarly, Tsebelis (1995) differentiates discipline - "the ability of parties to eliminate dissent after a decision is made" -from cohesion - "the size of differences [in policy preferences] before the discussion." (italics in original).
} 
results herein can be readily contrasted with the data, for this and other legislatures where roll call voting data is available.

The notion I introduce differs from what is the norm in the literature in the choice of the non-partisan framework to employ. In particular, this definition does not include changes in party members' voting behavior that are achieved with resources that could have otherwise been destined to non-party members (i.e., pork). This view emphasizes that allocating pork to party members means having to "buy" their support, and is therefore not an indication of power within the organization.

\subsection{The Leader as an Agent of the Majority of the Party}

I consider first the situation in which the incumbent leader has no access to spot resources $(R=0)$ and can be removed by the rebellion of a simple majority of the party $(\mu=$ $1 / 2$ ). I show that in this setting, credible promises of future partisan benefits confer only limited strength to the party leader, and a result similar in spirit to Aldrich and Rohde's conditional party governance (Aldrich and Rohde $(1997,1998)$ ) emerges: the incumbent leader will use promises of partisan benefits to support the party line only if the leadership's incentives are aligned (ex ante) with those of the majority of the party. Recall that $\theta_{0}$ denotes the ideal policy of the ex ante party median. Then:

Proposition 2 Let $R=0$ and $\mu=1 / 2$ be given. Then (i) party votes occur in equilib-

rium if and only if $v\left(\theta_{0}\right)<0$ (i.e., iff $x \succeq q$ ), and (ii) in party votes, the ex ante median is in the incumbent's coalition: $\delta_{p} \leq \theta_{0}$.

To see the intuition for this result, consider Figure 1. Recall that PBs use the information contained in their own ideal policy, as well as the location of the ex ante median to estimate the distribution of preferences within the party. A PB with ideal policy equal to the ex ante median believes he is exactly centrist, with half the party being more right-winged and half being more left-winged than himself. By the nature of the equilibrium strategies, if this $\mathrm{PB}$ is also the critical $\mathrm{PB}$, he will believe that half the party will support the incumbent and the other half will oppose her. Then since here $\mu=1 / 2$, he must attach probability $1 / 2$ to the incumbent falling, and therefore a (net) value of zero to her promises (note in the figure that $p(\delta)=0$ at $\delta=\theta_{0}$ ). Since $e p(\delta)$ is continuously decreasing, but everywhere flatter than $v(\delta)$, then for positive discipline we must have $\delta_{p}<\theta_{0}$. But this is only possible if the ex ante median $\theta_{0}$ prefers $x$ to $q$ (if $\left.\theta_{0}>\delta_{n p} \equiv \frac{x+q}{2}\right)$.

Note that this result holds independently of the level of partisan benefits available to the incumbent leader. The general moral is that even if credible per se and significant in amount, promises of future benefits will be relevant to alter voting behavior only if party members believe that the incumbent leader has a strong hold to the reins of power. Proposition 2 shows that with no resources to distribute on the spot, the leadership of a 
majoritarian institution is instead unstable (or more appropriately conditionally stable) and influence follows from the bottom up: promises are useful (and used) only if ex ante a majority of the party agrees with the incumbent leader on the ranking of alternatives in the first place.

The next proposition shows that the (limited) power that electoral benefits confer to the leadership in this environment can be attributed entirely to the heterogeneity of policy preferences among party backbenchers. That is, party discipline is monotonically increasing with the heterogeneity of party members' preferences, and vanishes in the limit as this heterogeneity goes to zero.

Proposition $3^{14}$ Let $R=0$ and $\mu=1 / 2$ be given. In equilibrium, discipline in party votes decreases with the homogeneity of $P B s^{\prime}$ preferences, and $\underset{\sigma \rightarrow 0}{\operatorname{Lim}} d=0$.

To get an intuition for this result, recall that PBs use both (i) public information about the central tendency of the party and (ii) the information contained in their own preferences to form beliefs about the distribution of fellow party members' preferences (and thus ultimately about their actions). When party members' preferences are heterogeneous, only the ex ante median believes he is "centrist", attaching equal probability to any member having ideal policy higher or lower than his own. PBs with ideal policy $\theta_{i}<\theta_{0}$, instead, believe that a majority of the party is to the left of the ex ante median. The informational content of a PB's ideal policy, in turn, increases with the homogeneity of the party. This implies, in particular, that PBs with ideal policy $\theta_{i}<\theta_{0}$ will attach a higher probability to the incumbent being overthrown (and thus a lower value to her promises of electoral benefits) the more homogeneous the party is. Note, however, that we are not concerned with how any arbitrary $P B$ forms its beliefs, but with how the critical $\mathrm{PB} \delta_{p}$ does. But we know from proposition 2 that when the incumbent can be overthrown by a simple majority of rebelling $\mathrm{PBs}$, the critical $\mathrm{PB} \delta_{p}$ assigns positive value to the incumbent's promises of electoral benefits only if the ex ante median is in the incumbent's coalition; i.e., only if $\delta_{p}<\theta_{0}$. The previous argument then implies that if discipline is positive, it must decrease with an increase in the homogeneity of PBs' preferences. $^{15}$

Heterogeneity is crucial here in that it allows the possibility of conflict, which the leader can exploit to bolster the support for the party line. In fact, as the previous result shows, in the naked setting of proposition 3 this is all the leader has, and as PBs are almost perfectly homogeneous, a leader that needs the support of a majority of the party

\footnotetext{
${ }^{14}$ For the proof, see that of proposition 5 , which includes this as a special case.

${ }^{15}$ Opposite to the case of heterogeneous preferences, where as I noted only the ex ante median believes he is "centrist", in the limit as $\sigma$ goes to zero every individual believes he is "centrist" (as no weight is given to the ex ante median). But then for the critical PB, whose ideal policy coincides with the symmetric strategy's cutoff point, electoral benefits offered by the incumbent must have no value. This means that electoral benefits will have no bite in equilibrium, and therefore discipline must vanish in equilibrium as $\sigma$ goes to zero.
} 
is powerless against the collective principal. In other words, it is the only when there is conflict and uncertainty about the position of fellow party legislators that the leader can be powerful with (just) promises of future benefits. ${ }^{16}$

\subsection{Vote Buying}

The analysis so far assumed that the incumbent could be overthrown by a simple majority of $\mathrm{PBs}$, and that the incumbent could not use resources other than the partisan electoral benefits to sway legislators' behavior. In this section I relax these assumptions. I show that while both innovations have the unambiguous effect of increasing the leader's power, they also have substantively different repercussions with respect to party backbenchers, the relation of the leader with the party, and the formation of legislative coalitions.

Being endowed with pork, the incumbent can now buy the support of legislators in the opposition. This, however, has an opportunity cost, as buying the opposition means weakening the support inside the party. The key to the results in this section is that this cost is magnified in a party vote as a result of a complementarity between the allocation of pork to party members and the value of promises of future partisan benefits. In a non-partisan vote - where PBs' beliefs about the actions of fellow party members are irrelevant - decreasing the allocation of pork to the party by one dollar leads to an equivalent reduction in the value of the incumbent's offer. In a party vote, instead, the value of the incumbent's promises of partisan benefits is tied to the fate of the leader. But a reduction in the allocation of pork to party members will induce PBs to anticipate a lower aggregate support for the party line and, as a result, a higher probability of the incumbent being overthrown, leading ultimately to a depreciation of the value of the incumbent's promises of partisan benefits.

The first implication of this logic is in the impact of endowing the leader with pork resources upon what I have referred to as conditional party governance. In the context of the previous section I showed that party benefits were used to favor the party line only when - according to public information - the majority of the party preferred the party line to the legislative alternative. When the incumbent can influence legislators' decisions with pork, however, party votes can exist in equilibrium even if $q \succ^{\theta_{0}} x$. Nevertheless, in the absence of a supermajority requirement for removal of the leader, the influence of backbenchers is not lost, but only reshaped in terms of a lower bound of payments that needs to be allocated to party members for party resources to be in play. In particular, the allocation of pork to party members has to be at least as large as to attain the support of the (ex ante) party median. The simple result follows, in effect, from the proof of proposition 2, and is stated in the following remark.

\footnotetext{
${ }^{16}$ With an underlying "social choice" model, Aldrich and Rodhe (1998) and Cox and McCubbins (1993) also argue that the power of the leader (the agenda setter) increases with the heterogeneity of party members' preferences. For a discussion of the differences between the two approaches, see section 6.
} 
Remark 3 Let $\mu=1 / 2$. If there is a party vote in equilibrium, $r \geq-v\left(\theta_{0}\right)$

Raising the bar for removal of the incumbent leader, instead, directly reduces the influence (and well-being) of backbenchers. Party discipline increases with the protection to the incumbent $1-\mu$, and therefore internal dissent is reduced even in the absence of compensations. Indeed, for every $\mu \in(0,1 / 2]$ there is a $r_{\min }(\mu)$ such that $r_{p}(\mu) \geq$ $r_{\min }(\mu)$ for a party vote to be possible in equilibrium, and it can be easily verified that $r_{\min }(\mu)$ is an increasing function, with maximum at $r_{\min }(1 / 2)=-v\left(\theta_{0}\right)$. Furthermore, the next proposition shows that when party votes occur in equilibrium, the incumbent will allocate less pork to buy opposition legislators the more contestable the leadership position is. The model thus predicts a subtle relationship between the allocation of pork, the power of nomination, and party's legislative institutions. More vulnerable leaders will enjoy less power from nominations. It is precisely this type of leaders, however, who will also tend to allocate more pork to buy the support of members of their own party, increasing discipline as a result.

Proposition 4 Suppose that the incumbent would call a party vote with $\mu=\mu^{0}$ and that $\mu^{1}<\mu^{0}$. Then $r_{p}\left(\mu^{0}\right) \geq r_{p}\left(\mu^{1}\right)$, with strict inequality if $r_{p}\left(\mu^{1}\right) \in\left(r_{\min }\left(\mu^{1}\right), R\right)$.

Note that this result holds even when, as here, the leader doesn't care about the leadership per se. In essence, the result is due to the fact that increasing the contestability of the leadership boosts the complementarity between pork and the value of electoral benefits. In this situation, "weak" leaders find more profitable buying their own party, thus avoiding large depreciations of the value of the future benefits at their disposal.

\subsection{Cohesion and Discipline Revisited}

In the context of Section 4.2, I showed that in equilibrium, discipline in party votes decreases with the homogeneity of PBs' preferences. Proposition 5 revisits this result, allowing for arbitrary majority requirements for removal and allocations of pork to party members. The proposition shows that provided $\mu=1 / 2$, the result does generalize to arbitrary $r \leq R$ as stated. When $\mu<1 / 2$, instead, the main intuition described above breaks down, and this is no longer the case. The gist of the argument is that with $\mu<1 / 2$, it is possible for the ex ante party median to be in the rebelling coalition, while still having positive discipline. When this is the case, the same argument used in proposition 3 shows that an increase in the heterogeneity of preferences will now diminish discipline.

Proposition 5 Let $\mu=1 / 2$ and $r \in[0, R]$ be given. In equilibrium, discipline in party votes decreases with the homogeneity of $P B s^{\prime}$ preferences, and $\underset{\sigma \rightarrow 0}{\operatorname{Lim}} d=0$. With $\mu<1 / 2$, however, this is not necessarily so, and $\underset{\sigma \rightarrow 0}{\operatorname{Lim}} d>0$. 


\section{Extension: Endogenous Challenge}

In the setting of the basic model, I assumed that challenges to the incumbent party leader occurred if and only if she decided to call a party vote. In this section I endogeneize the challenge decision. Given the lesser role of pork in this stage, I take an allocation $r$ as given, and focus instead on the characteristics of the policy alternative being supported by the incumbent leader. ${ }^{17}$ I show that under the assumptions in this section, (i) the incumbent is only challenged in party votes. Moreover, I distinguish two sets of alternatives $x$ possibly being supported by the incumbent leader in party votes: a set of "moderate" policies $\{x: q \leq x \leq \widetilde{x}\}$ and a set of "radical" policies $\{x: x \geq \widetilde{x}\}$. I show that (ii) the incumbent is not challenged in party votes for moderate policies, but always challenged in party votes for radical policies. The basic model is thus a stylized description of this extended framework. After reviewing the amendments I impose to the model, I provide a formal statement of these results, and note its implications for the uniqueness of equilibrium outcomes.

\subsection{The Extended Model}

I will consider the following "challenge technology". After the incumbent's choice, PBs in a given set of potential challengers $\Omega$ simultaneously decide whether they will propose or not a challenge to the incumbent leader. I assume that the preferences of potential challengers are common knowledge, that $\left\{\theta_{i}: i \in \Omega\right\}$ is compact and let $\underline{\omega} \equiv \min \left\{\theta_{i}: i \in\right.$ $\Omega\}$. A challenge occurs if some potential challenger $i \in \Omega$ proposes a challenge. Denoting the challenge decision of individual $i \in \Omega$ by $c_{i}\left(\theta_{i} ; x\right) \in\{0,1\}$, and by $c(x) \in\{0,1\}$ the occurrence of a challenge, then $c(x)=1$ whenever $c_{i}\left(\theta_{i} ; x\right)=1$ for some $i \in \Omega$, and $c(x)=0$ otherwise. Proposing the challenge is costless, and provides no special benefits (in the event the challenge is successful) vis a vis the remaining PBs opposing the incumbent leader.

I modify the definition of equilibrium to exclude equilibria containing weakly dominated strategies. I also replace A1 with the following (more demanding) assumption about PBs' preferences: ${ }^{18}$

Assumption (A1'). For every $x$, there exists $\bar{\alpha} \geq \underline{\alpha}>0$ s.t. for all $\left(\theta_{i}, \theta_{i}^{\prime}\right)$ with $\theta_{i}^{\prime}>\theta_{i}$,

$$
\bar{\alpha}(x-q)\left(\theta_{i}^{\prime}-\theta_{i}\right) \geq v\left(\theta_{i} ; x\right)-v\left(\theta_{i}^{\prime} ; x\right) \geq \underline{\alpha}(x-q)\left(\theta_{i}^{\prime}-\theta_{i}\right)
$$

\footnotetext{
${ }^{17}$ In our formulation, pork allocations are unalterable, and therefore are not the prime determinants of challenges to the incumbent leader. The central elements, instead, are given by the policy alternatives being considered and the allocation of electoral benefits.

${ }^{18}$ Note that this is also satisfied by a quadratic utility function $u\left(x_{i} ; \theta_{i}\right)=-b\left(x_{i}-\theta_{i}\right)^{2}$ (here $\bar{\alpha}=\underline{\alpha}=$ 2b)
} 


\subsection{Main Result, and Implications for Uniqueness of Equilib- rium Outcomes}

Proposition 1 showed that given any pair of policy alternatives $(q, x)$, the party vote game has a unique equilibrium provided there is sufficient uncertainty about the central tendency of the party. Specifically, keeping $q$ fixed, I showed that for any $x$ there is a $\bar{\eta}(x)$ such that a party vote equilibrium is unique whenever $\eta>\bar{\eta}(x)$. Under reasonable assumptions about preferences, however, $\bar{\eta}(x)$ decreases with $|x-q|$, and $\operatorname{Lim}_{x \rightarrow q} \bar{\eta}(x)=\infty$. Thus for fixed $\eta$, there is an $x$ sufficiently close to $q$ such that $\eta<\bar{\eta}(x)$, and the sufficient condition for uniqueness is not met. Note, however, that while the absence of policydriven conflict allows for multiple resolutions of a challenge should one occur, it also diminishes the benefit of mounting the challenge in the first place. Proposition 6 shows that if PBs are sufficiently uncertain about the distribution of fellow party members preferences, and challengers do not use weakly dominated strategies, challenges occur in equilibrium only for "radical" alternatives, and these always have a unique resolution.

Proposition 6 There exists a $\bar{\eta}$ such that for all $x>q$, whenever $\eta>\bar{\eta}: c(x)=1 \Rightarrow$ $\eta>\bar{\eta}(x)$. Moreover, for each $\eta>\bar{\eta}$ there exists a $\widetilde{x}_{\eta} \in R$ such that $c(x)=1 \Leftrightarrow x \geq \widetilde{x}_{\eta}$.

With the more stringent assumption (A1'), the basic model in the paper can thus be seen as a reduced form of this extended framework, provided that alternatives are "not too close" in the policy space. More precisely, if $x \in\left\{z \in \mathrm{R}: z \geq \widetilde{x}_{\eta}\right\}$ (if $x$ is in the set of "radical" policies), the incumbent is challenged if and only if the vote is a party vote, and challenges have a unique resolution. For moderate policies $\left\{x: q \leq x \leq \widetilde{x}_{\eta}\right\}$, instead, in equilibrium the incumbent is not even challenged in party votes. When policy-driven conflict is low, the model boils down to a standard model of unidirectional influence. Then again, it is in these situations where there is no scope for exercising power in the first place.

Establishing uniqueness of equilibria in the extended framework is specially relevant for the analysis of a policy choice stage, which I am not undertaking in this paper in order to concentrate on tradeoff between resources available to the leader and the contestability of the leadership position. The partition of the policy space in a set of moderate and radical alternatives implicit in proposition 6 implies immediately that discipline will be monotonically decreasing with $x$. Moreover, assuming that the party leader has agenda setting power, we can apply fairly directly some of our previous conclusions regarding spot payments to her choice of party line. In addition to its direct effect, the party line has an indirect component operating through its effect on backbenchers' beliefs regarding the incumbent survival. An "extreme" party line (relative to the preferred position of the ex ante median) conveys information to all PBs regarding general discontent with the incumbent's choice, and thus lowers the impact of promises of future benefits. An obvious implication of this logic is that discipline falls with $x$ faster than in a unidirectional model of influence, and faster the more vulnerable the leader is to internal challenges. I leave for future work a more complete analysis of this important topic. 


\section{Relation with the Literature}

\section{1 (Non-formal) Political Science Literature}

The predominant view among scholars studying European and Latin American legislative party organizations (as well as those prevalent in early theories of legislative leadership) grants significant power to party leaders. Leaders, it is argued, have wide discretion over the allocation of partisan resources, and based on their control of nominations, committee assignments, and other resources alike, are able to discipline backbenchers to follow the party line against their own preferences. ${ }^{19}$ Implicit in this view is the notion that leaders "are not checked by those who hold subsidiary positions within the organization" (Casinelli (1953), Michels (1962)).

Absent from the leaders-as-generals approach is the fact that leaders cannot lead without the support of their followers (McKenzie (1964), Jones (1968), Panebianco (1988), Calvert (1987), Sinclair (1983), Cox and McCubbins (2005b)). ${ }^{20}$ The reaction to this mismatch led to the currently predominant theories of legislative leadership in the US, which conceive leaders as "agents" of the rank and file (Sinclair (1983), Kiewit and McCubbins (1991), Aldrich and Rodhe (1998), Cox and McCubbins (1993)). The leader-as-agent analogy, however, is not without problems, or at least not if the analogy is to be drawn with standard principal agent theory in economics (Cox and McCubbins (2005a)). The relevant wedge is the substantial heterogeneity of preferences within the party that is typical in modern legislative parties but completely absent from standard principal-agency theory in economics. Here the problems of adverse selection and moral hazard so common in the formal approaches play a much lesser role. Instead, the substantial "agency problem" in this relationship is what Kiewit and McCubbins (1991) dub Madison's dilemma; that the resources or authority turned over to the "agent" for the purpose of furthering the interests of the principals can be turned against them. ${ }^{21}$

Aldrich and Rohde $(1997,1998)$ attempted to address this shortcoming in their theory of conditional party governance. In their view, the rank and file simply does not delegate the powers to the leadership unless their views are sufficiently homogeneous: "If there is much diversity in preferences within a party, a substantial portion of the members will be reluctant to grant strong powers to the leadership, or to resist the vigorous exercise of existing powers, because of the realistic fear that they may be used to produce outcomes unsatisfactory to the members in question." Aldrich and Rodhe (1997). When preferences are sufficiently homogeneous, instead, this delegation occurs, and the structure of the leader's incentives makes her "internalize the goals of the members, and therefore behave to a large extent in the party members' best interest." (Cox and McCubbins

\footnotetext{
${ }^{19}$ See any of the contributions in Morgenstern and Nacif, eds (2002) or Bowler et al., eds (1999)

${ }^{20}$ Moreover, empirically, the leaders-as-generals approach can't account for the wide variation in the available measures of discipline across countries with similar electoral rules, across parties within the same country, and across different periods within the same party (see for example Morgenstern (2004)).

${ }^{21}$ The first to recognize the shift in focus, however, are the proponents of the agency theory of leadership themselves. See for example Kiewit and McCubbins (1991).
} 
$(1993)) \cdot{ }^{22}$

In this paper, I build on Aldrich and Rohde's approach, while emphasizing a markedly different timing and coordination of the collective (heterogeneous) principal. It is not the choice of a single PB, I argue, to "resist the vigorous exercise of existing powers". Instead, resisting the exercise of existing powers, or removing existing powers, is a collective choice determined by the common knowledge of opposition to the incumbent. The explicit consideration of how this impure coordination problem is resolved is then essential to understand the limits of the incumbent's power over legislators. From this perspective, the alternative views expressed in the leaders-as-generals and leaders-as-agents traditions can be taken to represent opposite assumptions about the degree of difficulty for the rank and file to effectively coordinate in opposing their leaders; i.e., in constituting an effective check to the leader's power: while this coordination is precluded outright in the world of the iron law of oligarchy (Michels (1962)), it is assumed to work without frictions in the conditional party governance framework of Aldrich and Rohde and the cartel theory of Cox and McCubbins.

\subsection{Formal Literature}

The early formal literature of legislatures and elections either treated parties as unitary actors or ignored them altogether. In recent years, a second generation of research in formal political economy has started to fill this gap.

A first group takes discipline in legislatures as given and focuses on how parties as organizations alter the number and characteristics of electoral alternatives. ${ }^{23}$ Closest to this paper among these are Snyder and Ting (2002) and Ashworth and Bueno de Mesquita (2006). Snyder and Ting (2002) take the number of parties (two) as given, but allow candidates in different districts to choose which party to join, if any, after observing parties' choices of platforms. Elected candidates affiliated with a party face a cost (which the authors interpret as discipline) which is increasing in the distance

\footnotetext{
${ }^{22}$ The seminal contributions by Cox and McCubbins (Cox and McCubbins (1993), Cox and McCubbins (2005b)) share this perspective and build on it, distinguishing between positive and negative agenda power. While conditional party governance describes positive agenda power, negative agenda power is unconditional.

${ }^{23}$ In Alesina and Spear (1988), intergenerational transfers allow (finitely lived) politicians within the (infinitely lived) party to credibly choose a policy different than his or her own ideal policy, in Roemer (1999) the party platform is a compromise among internal factions with different preferences for holding office and determining policy. Levy (2004), Morelli (2004), and Osborne and Tourky (2004) all analyze endogenous party formation. Levy (2004) focuses on the role of parties as institutions that allow politicians to commit to a platform other than their own ideal policy. Morelli (2004) argues that parties facilitate coordination among voters, and studies how plurality and PR electoral systems influence party formation and policy choice. Osborne and Tourky (2004) study a citizen-candidate model where "parties" (sets of individuals who "champion the same policy") reduce the costs of "championing a policy". Caillaud and Tirole (2002) and Mattozzi and Merlo (2005) also focus on the influence of parties at the electoral stage, but emphasize instead their role in the selection of candidates. See Merlo (2005) for a review of work in these areas.
} 
between their ideal policy and the party platform. As a result of the endogenous sorting induced in equilibrium, party labels provide information to voters about the preferences of politicians. Building on Snyder and Ting (2002), Ashworth and Bueno de Mesquita (2006) provide a model in which party discipline is endogenously determined. Here party platforms are taken as given, but the levels of "discipline" are optimally chosen by the party leaders. Ashworth and Bueno de Mesquita (2006) therefore focus on discipline from an ex ante, institutional design perspective. In the current paper, instead, I have taken party institutions as given, and focused on how effective discipline is affected in equilibrium by backbenchers' beliefs about the continuity of the incumbent (and the party line).

A second group of papers focuses on the influence of parties at the policy determination stage building on the seminal - and party-less - Baron and Ferejohn (1989) model of legislative bargaining. ${ }^{24}$ Calvert and Dietz (1998) generate cohesive, party-like voting by introducing externalities in an otherwise standard Baron and Ferejohn (1989) model, but (aware of Krehbiel (1993)'s critique) suggest to think of parties as "nonstationary equilibrium institutions". This proposal is undertaken by Calvert and Fox (2003), who show the existence of a nonstationary equilibrium of the BF satisfying properties of "partisan" behavior. ${ }^{25}$ Jackson and Moselle (2002), instead, see parties are institutions external to the game that facilitate commitment "to follow the same single action when recognized, and to approve each other's proposals" (see Baron (1989) for a similar assumption). With this perspective about parties, Jackson and Moselle analyze endogenous party formation within a modified BF model in which decisions are made over both ideological and distributive dimensions. Diermeier and Feddersen (1998) also obtain cohesive voting not being driven by preference homogeneity as an equilibrium of a modified Baron and Ferejohn (1989) model. In their model, however, cohesive voting is not associated to partisan behavior, but instead to the "vote of confidence procedure", an institutional feature of parliamentary systems which ties the success of a bill to the continuation of government (see also Huber (1996)). This alternative argument - competing with the partisan theories such as the one I present here in terms of their quantitative significance to explain observed levels of discipline across polities - should be regarded as complementary with the partisan approach. ${ }^{26}$

Two recent contributions (Myerson (2005) and Bueno de Mesquita et al. (1999, 2002, 2003)) are directly concerned with challenges to incumbent leaders. Myerson (2005) also

\footnotetext{
${ }^{24}$ But see also Laver and Shepsle (1990), who focus on the role of intraparty politics in coalition and government formation.

${ }^{25}$ Members of the majority have higher equilibrium payoffs, in non-punishment phases their proposals allocate more to fellow majority members than to members of the minority, and deviations are followed by punishment phases of finite length.

${ }^{26}$ While parliamentary systems are (according to most observers) associated with high levels of cohesion in voting, the difference in parliamentary and presidential systems is not powerful enough to explain the observed variation in discipline across polities, across parties in the same country, and across periods for the same party. In fact, Diermeier and Feddersen (1998)'s motivation for presidential systems focuses heavily on the US Congress. Even here, as they themselves argue, policy coalitions are hardly modified issue to issue, and the available measures of discipline display significant variation throughout history.
} 
takes as a starting point that leaders "can win and hold power against challengers only with the costly efforts of many supporters who must expect rewards from his success", but stresses that leaders cannot be expected to reward the effort of followers if they can find alternative sources of support. This problem is solved, he argues, by "constitutions": agreements - the terms of which can be monitored by activists - that require the leader to share the spoils of power. ${ }^{27}$ Bueno de Mesquita et al. (1999, 2002, 2003) focus on how variations in the size of the "selectorate" and in the relative size of the coalition necessary to replace leaders (what I have called $\mu$ in this paper) influence the incumbent's optimal allocation of resources between public goods and pork. The effect of beliefs about the leader's survival so heavily emphasized here is completely secondary in Bueno de Mesquita et al. $(1999,2002,2003)$ because of their focus on a particular equilibrium of the game.

\section{Concluding Remarks}

This paper built on two basic elements characterizing leadership in political parties. First, leaders need to maintain a minimum level of support to continue leading. Second, at least some of the resources available to the leadership are promises of future benefits, which can only be delivered if the incumbent retains the command of the party. As a result, discipline will be endogenously determined by backbenchers' beliefs about the extent of support to the incumbent among other party legislators. More generally, while discipline will be affected by the nature and amount of resources available to the leaders, the impact of these various instruments will be filtered by how each of them contributes to backbenchers' expectations about the incumbent's survival. Building on these main insights, the paper provided several novel empirical implications for the comparative analysis of parties and legislatures, which can contribute to account for the wide unexplained variation in the available measures of discipline across countries with similar electoral rules, across parties within the same country, and across different periods within the same party. Most of these results, moreover, can also be naturally applied to address behavior in other types of organizations such as firms, unions, autocratic governments and organized crime.

Several avenues for future research seem worth pursuing. A natural next step is to relax the simplicity of the current vote buying model to study optimal size and composition of partisan coalitions. Modeling dynamics would also allow us to analyze whether an incumbent would optimally engage in vote buying at the initial phase or the end of her tenure. Along the same avenue, it would be interesting to extend this model along the lines of Angeletos et al. (2006) to focus on the dynamics of discipline and revolts. A second natural next step is to focus on the policy choice stage, the analysis of which I am not undertaking in this paper to concentrate on the tradeoff between resources available

\footnotetext{
${ }^{27}$ These constitutions, moreover, serve a role in equilibrium selection. As in this paper, the fact that individuals want to be aligned with the winning side leads in Myerson (2005) to multiple equilibria. According to Myerson, however, coordination on the incumbent's preferred equilibrium depends on her/him following behavior specified in the agreement.
} 
to the leader and the contestability of the leadership position. Establishing uniqueness of equilibria in the extended framework of section 5 was important to facilitate this future research. 


\section{Appendix}

Proof of Remark 2. Consider first strategy profile (1). Since $\theta_{i} \mid \theta \sim N\left(\theta, \sigma^{2}\right)$, the proportion of PBs voting for $x$ is then given by $1-\Phi\left(\frac{\theta_{i}-\theta}{\sigma}\right)$, where $\Phi(\cdot)$ is the c.d.f. of the standard normal. The incumbent survives the challenge (with certainty) if

$$
1-\Phi\left(\frac{\theta_{i}-\theta}{\sigma}\right)>\mu \Leftrightarrow \theta>\underline{\theta_{i}}-\sigma \Phi^{-1}(1-\mu)
$$

Since this is true by hypothesis, the expected net payoff of voting for $q$ for $\mathrm{PB} i$ is given by $v\left(\theta_{i}\right)-r-e$. Then optimality implies $\varkappa_{i}^{p}\left(\theta_{i} ; r\right)=q$ if $\theta_{i}<v^{-1}(r+e) \equiv \underline{\theta_{i}}$ and $\varkappa_{i}^{p}\left(\theta_{i} ; r\right)=x$ if $\theta_{i}>\underline{\theta_{i}}$. Similarly, consider strategy profile (2). The proportion of PBs voting for $x$ is then given by $1-\Phi\left(\frac{\overline{\theta_{i}}-\theta}{\sigma}\right)$. The incumbent leader will fall for sure if $1-\Phi\left(\frac{\overline{\theta_{i}}-\theta}{\sigma}\right)<\mu \Leftrightarrow \theta<\overline{\theta_{i}}-\sigma \Phi^{-1}(1-\mu)$, which again is true by hypothesis. The expected net payoff of voting for $x$ for $\mathrm{PB} i$ is then given by $r-e-v\left(\theta_{i}\right)$, and optimality implies $\varkappa_{i}^{p}\left(\theta_{i} ; r\right)=x \forall i: \theta_{i}>\overline{\theta_{i}}$ and $\varkappa_{i}^{p}\left(\theta_{i} ; r\right)=q \forall i: \theta_{i}<\overline{\theta_{i}}$.

Proof of Proposition 1. The following definitions will be used here. For a given strategy profile of the party vote game $\left\{\varkappa_{i}^{p}\right\}$, where each $\varkappa_{i}^{p}: \Theta \times[0, R] \rightarrow\{q, x\}$, let $\xi(z)$ denote the proportion of PBs for whom $\varkappa_{i}^{p}(z ; r)=x$, let $\Gamma(\theta ; \xi)$ denote the proportion of PBs that would end up supporting $x$ given a particular realization of $\theta$ and an aggregate voting mapping $\xi$, and let $\Pi\left(\theta_{i} ; \xi\right)$ denote the expected net benefit of supporting $x$ for a $\mathrm{PB}$ with ideal policy $\theta_{i}$, given $\xi$.

Proposition 1 follows from three lemmas. In Lemma 1, I show that $(i)\{\delta: \pi(\delta)=$ $0\} \neq \varnothing$, and that (ii) with $\delta_{p} \in\{\delta: \pi(\delta)=0\}$, there exists a symmetric equilibrium of the party vote game in which $\varkappa_{i}^{p}\left(\theta_{i}, r\right)=x$ for all i such that $\theta_{i} \geq \delta_{p}$ and $\varkappa_{i}^{p}\left(\theta_{i}, r\right)=q$ for all $\mathrm{i}$ such that $\theta_{i}<\delta_{p}$. In Lemma 2 I show that if $\pi(\delta)$ is strictly increasing $\{\delta$ : $\pi(\delta)=0\}$ has a single element $\delta_{p}$, and this equilibrium is unique. The next step is thus to provide a sufficient condition for $\pi(\delta)$ to be strictly increasing. Note that this happens iff $e p^{\prime}(\delta)>v^{\prime}(\delta)$ for every $\delta$, and that we know already that $v(\cdot)$ is a strictly decreasing function. Lemma 3 shows that while $p(\delta)$ is also a decreasing function, it can be made arbitrarily flat by reducing the precision of public information (by increasing $\eta$ ). Specifically, for any $Q>0$, there exist a $\bar{\eta}(Q)$ such that if $\eta>\bar{\eta}(Q)$, then $\left|p^{\prime}(\delta)\right|<Q$. Then $\pi(\delta)$ is strictly increasing if $\eta>\bar{\eta}\left(\frac{1}{e}\left|v^{\prime}(\delta)\right|\right)$, and we are done.

Lemma $1\{\delta: \pi(\delta)=0\} \neq \varnothing$. Let $\delta_{p} \in\{\delta: \pi(\delta)=0\}$. There exists a symmetric equilibrium of the party vote game in which $\varkappa_{i}^{p}\left(\theta_{i}, r\right)=x$ for all $i$ such that $\theta_{i} \geq \delta_{p}$ and $\varkappa_{i}^{p}\left(\theta_{i}, r\right)=q$ for all $i$ such that $\theta_{i}<\delta_{p}$.

Proof. Our first task is to show that $\{\delta: \pi(\delta)=0\} \neq \varnothing$. Consider the points $\underline{\theta_{i}} \equiv v^{-1}(r+e)$ and $\overline{\theta_{i}} \equiv v^{-1}(r-e)$ that were defined in Remark 2. Note that the net 
payoff of voting for $q$ for PB $i$ in the event that the incumbent survives the challenge is given by $v\left(\theta_{i}\right)-r-e$. Since the net payoff of voting for $q$ for PB $i$ is always at least $v\left(\theta_{i}\right)-r-e$, then $\theta_{i}<\underline{\theta}_{i} \Rightarrow \Pi\left(\theta_{i} ; \xi\right)<0$ for any $\xi$. Similarly, since the net payoff of voting for $x$ for $\mathrm{PB} i$ is always at least $r-e-v\left(\theta_{i}\right)$ (where the challenge is succesful for sure), then $\theta_{i}>\bar{\theta}_{i} \Rightarrow \Pi\left(\theta_{i} ; \xi\right)>0$ for any $\xi$. It should be noted that the points $\bar{\theta}_{i}$ and $\underline{\theta}_{i}$ are well defined, since $v(\cdot)$ is continuously decreasing, and $\underset{\theta_{i} \rightarrow-\infty}{\operatorname{Lim}} v\left(\theta_{i}\right)=\infty$, while $\operatorname{Lim}_{\theta_{i} \rightarrow \infty} v\left(\theta_{i}\right)=-\infty$ by A1. Now, $\pi(\delta) \equiv \Pi(\delta, \delta) \equiv \Pi\left(\theta_{i}=\delta ; \xi=1_{\left\{\theta_{i} \geq \delta\right\}}\right)$. Then the previous argument implies, in particular, that $\pi(\delta)>0$ for $\delta>\bar{\theta}_{i}$, and $\pi(\delta)<0$ for $\delta<\underline{\theta}_{i}$. Since $\pi(\delta)$ is continuous, this implies that $\{\delta: \pi(\delta)=0\} \neq \varnothing$. Next, let $\delta_{p} \in\{\delta: \pi(\delta)=0\}$. To show the existence of the symmetric equilibrium, it is now enough to show that $\Pi\left(\theta_{i} ; 1_{\left\{\theta_{i} \geq \delta\right\}}\right)$ is increasing in $\theta_{i}$. But it is easy to see from (1) that $P\left(\delta, \theta_{i}\right)$ is increasing in $\theta_{i}$. Since $v\left(\theta_{i}\right)$ is decreasing, the result follows.

Lemma 2 Suppose that $\pi(\delta)$ is strictly increasing. Then $\{\delta: \pi(\delta)=0\}$ has a single element $\delta_{p}$, and the equilibrium of Lemma 1 is unique.

Proof (Morris and Shin (1998). If $\pi(\delta)$ is stricly increasing, there is a unique $\delta_{p}$ solving $\pi(\delta)=0$. I show next that this in turn implies that the symmetric equilibrium with switching strategies at $\delta_{p}$ is the unique equilibrium. So consider any equilibrium of the game, and define the numbers

$$
\underline{z} \equiv \inf \{z \mid \xi(z)>0\} \text { and } \bar{z} \equiv \sup \{z \mid \xi(z)<1\}
$$

Note first that

$$
\begin{aligned}
\bar{z} \equiv \sup \{z \mid \xi(z) & <1\} \geq \sup \{z \mid 0<\xi(z)<1\} \\
& \geq \inf \{z \mid 0<\xi(z)<1\} \geq \inf \{z \mid \xi(z)>0\} \equiv \underline{z}
\end{aligned}
$$

Now, for any $z \in\{z \mid \xi(z)>0\}$, there is some $i$ for which $x_{i}^{p}(z ; r)=x$. This is only consistent with equilibrium behavior if the payoff to supporting $x$ (for $\mathrm{mr} i$ and for anyone else, since they are all identical, ex ante) is at least as high as the payoff to supporting $q$ given ideal policy $z$; i.e., $\Pi(z, \xi) \geq 0$. By continuity, this is also true at $\underline{z}$; i.e.,

$$
\Pi(\underline{z}, \xi) \geq 0
$$

Now consider the payoff $\Pi\left(\underline{z}, 1_{\left\{\theta_{i} \geq \underline{z}\right\}}\right)$. It is clear that, for any $z, 1_{\left\{\theta_{i} \geq \underline{z}\right\}}(z) \geq \xi(z)$. But - in general - whenever $\xi(z) \geq \xi^{\prime}(z)$ for any $z$, then $\Pi(z, \xi) \geq \Pi\left(z, \xi^{\prime}\right)$. Hence $\Pi\left(z, 1_{\left\{\theta_{i} \geq z\right\}}\right) \geq \Pi(z, \xi)$ for any $z$, and in particular

$$
\pi(\underline{z}) \equiv \Pi\left(\underline{z}, 1_{\left\{\theta_{i} \geq \underline{z}\right\}}\right) \geq \Pi(\underline{z}, \xi)
$$


Thus combining (2) and (3) I obtain

$$
\pi(\underline{z}) \geq 0
$$

Now by hypothesis, $\pi(\delta)$ is increasing in $\delta$. Since $\delta_{p}$ is the unique value of $\delta$ which solves $\pi(\delta)=0$, this means $\underline{z} \geq \delta_{p}$. A symmetric argument establishes that $\bar{z} \leq \delta_{p}$. Thus $\bar{z} \leq \delta_{p} \leq \underline{z}$. This together with (IS) implies that $\underline{z}=\delta_{p}=\bar{z}$. Thus in any equilibrium the $x$ 's aggregate support mapping $\xi$, and thus the strategy of every $\mathrm{PB}, x_{i}^{p}$, is given by $1_{\left\{\theta_{i} \geq \delta_{p}\right\}}$.

Lemma $3 p(\cdot)$ is a decreasing function of $\delta$. Furthermore, for any $Q>0$, there exists a $\bar{\eta}(Q)$ such that if $\eta>\bar{\eta}(Q)$, then $\left|p^{\prime}(\delta)\right|<Q$

Proof. Since

$$
\left(\frac{\theta-\widehat{\theta}\left(\theta_{i}\right)}{\widehat{\eta}}\right)_{\theta=\delta-\sigma \Phi^{-1}(1-\mu)}=\frac{1}{\widehat{\eta}}\left[\frac{\sigma^{2}\left(\delta-\theta_{0}\right)+\eta^{2}\left(\delta-\theta_{i}\right)}{\sigma^{2}+\eta^{2}}-\sigma \Phi^{-1}(1-\mu)\right]
$$

, then

$$
p(\delta)=P(\delta, \delta)=1-2 \Phi\left(\frac{1}{\widehat{\eta}}\left[\frac{\sigma^{2}}{\sigma^{2}+\eta^{2}}\left(\delta-\theta_{0}\right)-\sigma \Phi^{-1}(1-\mu)\right]\right)
$$

Hence

$$
\frac{\partial p(\delta)}{\partial \delta}=-2 \phi\left(\frac{1}{\widehat{\eta}}\left[\frac{\sigma^{2}}{\sigma^{2}+\eta^{2}}\left(\delta-\theta_{0}\right)-\sigma \Phi^{-1}(1-\mu)\right]\right) \frac{1}{\eta} \frac{1}{\sqrt{1+\frac{\eta^{2}}{\sigma^{2}}}}
$$

That $p^{\prime}(\delta)<0$ follows immediately. And since $\left|p^{\prime}(\delta)\right|$ is bounded above by $\frac{2}{\eta},\left|p^{\prime}(\delta)\right|<$ $Q$ for $\eta>2 / Q=\bar{\eta}(Q)$.

Proof of Proposition 2. First note that the incumbent will call a party vote in equilibrium if and only if discipline is positive. Now, $d=\delta_{n p}-\delta_{p} \geq 0 \Leftrightarrow p\left(\delta_{p}\right) \geq 0$. That is, discipline is positive if and only if the critical PB $\delta_{p}$ assigns net positive value to the incumbent's promises of electoral benefits. But with $\mu=1 / 2, p\left(\delta_{p}\right) \geq 0 \Leftrightarrow \delta_{p} \leq \theta_{0}$, because

$$
\operatorname{Pr}\left(\Gamma\left(\theta, \delta_{p}\right)<\mu \mid \theta_{i}=\delta_{p}\right)=\operatorname{Pr}\left(\theta<\delta_{p} \mid \theta_{i}=\delta_{p}\right)<1 / 2 \Leftrightarrow \delta_{p}<\theta_{0}
$$

That is, with $\mu=1 / 2$, the critical $\mathrm{PB} \delta_{p}$ assigns net positive value to the incumbent's promises of electoral benefits if and only if the ex ante party median is in the incumbent's coalition (iff $\delta_{p}<\theta_{0}$ ). Hence $d \geq 0 \Leftrightarrow \delta_{p} \leq \theta_{0}$. Now, with $r=0, \delta_{n p}=v^{-1}(0)$, and then $v\left(\delta_{n p}\right)=0$. Since $e p(\delta)$ is continuously decreasing, but everywhere flatter than $v(\delta)$, 


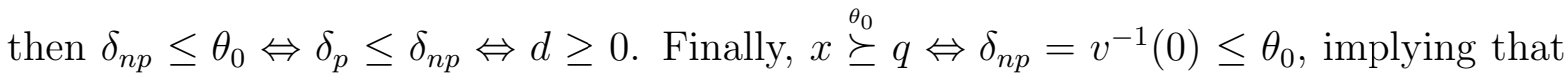
$x \succeq q \Leftrightarrow d \geq 0$.

Proof of Proposition 4. The first step is to characterize optimal allocations of pork to party members under rule $\mu, r_{p}(\mu)$. Let $H(\cdot) \equiv\left[1-G\left(v^{-1}(\cdot)\right)\right]$. The mass of legislators in the opposition voting for $x$ given pork offer $r_{o}$ is given by $H\left(r_{o}\right) \beta$. Note that $H^{\prime}\left(r_{o}\right) \geq 0$ for all $r_{o}$. Pork resource constraint is given by $r_{o} \beta+r \leq R$. Since this will hold with equality in the optimum, I write $r_{o}=\frac{R-r}{\beta}$. Conditional on $\theta$, then, $y=x$ iff $H\left(\frac{R-r}{\beta}\right) \beta+\Gamma\left(\theta, \delta_{p}(r, \mu)\right) \geq \frac{(1+\beta)}{2}$. Since $\Gamma\left(\theta, \delta_{p}(r, \mu)\right)=1-\Phi\left(\frac{\delta_{p}(r, \mu)-\theta}{\sigma}\right)$, this is

$$
\theta \geq \delta_{p}(r, \mu)-J(r)
$$

, where $J(r) \equiv \sigma \Phi^{-1}\left(\frac{(1-\beta)}{2}+H\left(\frac{R-r}{\beta}\right) \beta\right)$. Then for the incumbent,

$$
\operatorname{Pr}(y=x)=1-\Phi\left(\frac{1}{\eta}\left[\left(\delta_{p}(r, \mu)-\theta_{0}\right)-J(r)\right]\right)
$$

An optimal allocation of pork for the incumbent $r_{p}(\mu)$ maximizes $\operatorname{Pr}(y=x)$. The FOC is:

$$
\left|\frac{\partial \delta_{p}\left(r_{p}(\mu), \mu\right)}{\partial r}\right|-J^{\prime}\left(r_{p}(\mu)\right)\left\{\begin{array}{ccc}
>0 & \text { and } & r_{p}(\mu)=R \\
=0 & \text { and } & r_{p}(\mu) \in\left(r_{\min }(\mu), R\right) \\
<0 & \text { and } & r_{p}(\mu)=r_{\min }(\mu)
\end{array}\right.
$$

The second and final step is to show that for all $r$

$$
\left|\frac{\partial \delta_{p}\left(r, \mu^{0}\right)}{\partial r}\right|>\left|\frac{\partial \delta_{p}\left(r, \mu^{1}\right)}{\partial r}\right| \text { whenever } \mu^{0}>\mu^{1}
$$

, which implies that

$$
\left|\frac{\partial \delta_{p}\left(r_{p}\left(\mu^{1}\right), \mu^{0}\right)}{\partial r}\right|>\left|\frac{\partial \delta_{p}\left(r_{p}\left(\mu^{1}\right), \mu^{1}\right)}{\partial r}\right| \text { whenever } \mu^{0}>\mu^{1}
$$

Then (7) together with (5) will imply that $r_{p}\left(\mu^{0}\right) \geq r_{p}\left(\mu^{1}\right)$. Moreover, if $r_{p}\left(\mu^{1}\right) \in$ $\left(r_{\text {min }}\left(\mu^{1}\right), R\right)$, so that $\left|\frac{\partial \delta_{p}\left(r_{p}\left(\mu^{1}\right), \mu^{1}\right)}{\partial r}\right|=J^{\prime}\left(r_{p}\left(\mu^{1}\right)\right)$, then $\left|\frac{\partial \delta_{p}\left(r_{p}\left(\mu^{1}\right), \mu^{0}\right)}{\partial r}\right|>J^{\prime}\left(r_{p}\left(\mu^{1}\right)\right)$, and hence $r_{p}\left(\mu^{0}\right)>r_{p}\left(\mu^{1}\right)$.

Note that for all $r, \mu$,

$$
\left|\frac{\partial \delta_{p}(r, \mu)}{\partial r}\right|^{-1}=\left|\frac{\partial v\left(\delta_{p}(r, \mu)\right)}{\partial \delta}\right|-e\left|\frac{\partial p\left(\delta_{p}(r, \mu) ; \mu\right)}{\partial \delta}\right|
$$


so that (6) can be written as:

$$
e\left\{\left|\frac{\partial p\left(\delta_{p}\left(r, \mu^{0}\right) ; \mu^{0}\right)}{\partial \delta}\right|-\left|\frac{\partial p\left(\delta_{p}\left(r, \mu^{1}\right) ; \mu^{1}\right)}{\partial \delta}\right|\right\}>\left|\frac{\partial v\left(\delta_{p}\left(r, \mu^{0}\right)\right)}{\partial \delta}\right|-\left|\frac{\partial v\left(\delta_{p}\left(r, \mu^{1}\right)\right)}{\partial \delta}\right|
$$

Note, next, that since in a party vote $\delta_{p}(r, \mu)$ is increasing in $\mu$, then $\delta_{p}\left(r, \mu^{1}\right)<$ $\delta_{p}\left(r, \mu^{0}\right)$. Assumption (A1) then implies that

$$
\left|v^{\prime}\left(\delta_{p}\left(r, \mu^{1}\right)\right)\right| \geq\left|v^{\prime}\left(\delta_{p}\left(r, \mu^{0}\right)\right)\right|
$$

Also, since

$$
\left|\frac{\partial p(\delta ; \mu)}{\partial \delta}\right|=2 \phi\left(\frac{1}{\widehat{\eta}}\left[\frac{\sigma^{2}}{\sigma^{2}+\eta^{2}}\left(\delta-\theta_{0}\right)-\sigma \Phi^{-1}(1-\mu)\right]\right) \frac{1}{\eta} \frac{1}{\sqrt{1+\frac{\eta^{2}}{\sigma^{2}}}}
$$

, it can be verified that if $d>0$ then $\frac{\partial}{\partial \mu}\left(\left|\frac{\partial p(\delta ; \mu)}{\partial \delta}\right|\right)>0$, so that

$$
\left|\frac{\partial p\left(\delta_{p}\left(r, \mu^{0}\right) ; \mu^{0}\right)}{\partial \delta}\right|>\left|\frac{\partial p\left(\delta_{p}\left(r, \mu^{0}\right) ; \mu^{1}\right)}{\partial \delta}\right|
$$

, and that (ii) $\frac{\partial^{2} p(\delta ; \mu)}{\partial \delta^{2}}<0$, so that $\delta_{p}\left(r, \mu^{0}\right)>\delta_{p}\left(r, \mu^{1}\right)$ implies that

$$
\left|\frac{\partial p\left(\delta_{p}\left(r, \mu^{0}\right) ; \mu^{1}\right)}{\partial \delta}\right|>\left|\frac{\partial p\left(\delta_{p}\left(r, \mu^{1}\right) ; \mu^{1}\right)}{\partial \delta}\right|
$$

Then (10) and (11) imply that

$$
\left|\frac{\partial p\left(\delta_{p}\left(r, \mu^{0}\right) ; \mu^{0}\right)}{\partial \delta}\right|>\left|\frac{\partial p\left(\delta_{p}\left(r, \mu^{1}\right) ; \mu^{1}\right)}{\partial \delta}\right|
$$

Then (9) and (12) imply that (8) holds.

Proof of Proposition 5. Note first that

$$
p(\delta)=P(\delta, \delta)=1-2 \Phi\left(\frac{1}{\widehat{\eta}}\left[\frac{\sigma^{2}}{\sigma^{2}+\eta^{2}}\left(\delta-\theta_{0}\right)-\sigma \Phi^{-1}(1-\mu)\right]\right)
$$

, where

$$
\frac{1}{\widehat{\eta}}\left[\frac{\sigma^{2}}{\sigma^{2}+\eta^{2}}\left(\delta-\theta_{0}\right)-\sigma \Phi^{-1}(1-\mu)\right]=\left(\frac{\theta-\widehat{\theta}\left(\theta_{i}=\delta\right)}{\widehat{\eta}}\right)_{\theta=\delta-\sigma \Phi^{-1}(1-\mu)}
$$


Thus

$$
\frac{\partial p(\delta ; \sigma)}{\partial \sigma}=-2 \phi(\cdot) \frac{1}{\sqrt{\sigma^{2}+\eta^{2}}}\left[\frac{\eta}{\sigma^{2}+\eta^{2}}\left(\delta-\theta_{0}\right)-\frac{\sigma}{\eta} \Phi^{-1}(1-\mu)\right]
$$

, so that $\frac{\partial p\left(\delta_{p} ; \sigma\right)}{\partial \sigma} \geq 0$ if and only if:

$$
\theta_{0} \geq \delta_{p}-\sigma \Phi^{-1}(1-\mu)\left(1+\frac{\sigma^{2}}{\eta^{2}}\right)
$$

But if $p(\delta ; \sigma)$ increases with $\sigma$ at $\delta_{p}\left(\sigma^{\prime}\right)$, then $\sigma^{\prime \prime}>\sigma^{\prime} \Longrightarrow \delta_{p}\left(\sigma^{\prime \prime}\right)<\delta_{p}\left(\sigma^{\prime}\right)$. Hence more heterogeneity of PBs' preferences must in this case increase discipline. Similarly, if $p(\delta ; \sigma)$ decreases with $\sigma$ at $\delta_{p}\left(\sigma^{\prime}\right)$, then more heterogeneity of PBs' preferences must in this case reduce discipline. Now,

$$
d \geq 0 \Leftrightarrow p\left(\delta_{p}\right) \geq 0 \Leftrightarrow\left(\frac{\theta-\widehat{\theta}\left(\theta_{i}=\delta_{p}\right)}{\widehat{\eta}}\right)_{\theta=\delta_{p}-\sigma \Phi^{-1}(1-\mu)} \leq 0
$$

That is, $d \geq 0$ if and only if

$$
\theta_{0} \geq \delta_{p}-\left(1+\frac{\eta^{2}}{\sigma^{2}}\right) \sigma \Phi^{-1}(1-\mu)
$$

Hence, in equilibrium, discipline in party votes necessarily increases with $\sigma$ if (13) is satisfied whenever (14) is. Since $\delta_{p}$ is a continuously decreasing function of $\theta_{0}$, bounded below by $\underline{\theta_{i}} \equiv v^{-1}(r+e)$ and above by $\overline{\theta_{i}} \equiv v^{-1}(r-e)$, there is a unique $\theta_{0}^{*}$ solving (13) with equality, and a unique $\theta_{0}^{* *}$ solving (14) with equality. If $\mu=1 / 2$, these two inequalities collapse to $\theta_{0} \geq \delta_{p}$. Therefore in equilibrium, discipline in party votes necessarily increases with $\sigma$. Moreover, $\delta_{p}=\theta_{0} \Leftrightarrow p\left(\delta_{p}\right)=0 \Leftrightarrow \theta_{0}=v^{-1}(r)$, so that $\theta_{0}^{*}=\theta_{0}^{* *}=v^{-1}(r)$. With $\mu<1 / 2$, however, (13) is satisfied whenever (14) is only if $\sigma \geq \eta$.

To establish the results for the limit as $\sigma \rightarrow 0$, we show that

$$
\operatorname{Lim}_{\sigma \rightarrow 0} d=v^{-1}(r)-v^{-1}(r+e[1-2 \mu])
$$

To see this, let

$$
\begin{aligned}
f(\sigma) & =\Phi\left(\left(\frac{\theta-\widehat{\theta}\left(\theta_{i}=\delta\right)}{\widehat{\eta}}\right)_{\theta=\delta-\sigma \Phi^{-1}(1-\mu)}\right) \\
& =\Phi\left(\frac{1}{\eta}\left(1+\frac{\eta^{2}}{\sigma^{2}}\right)^{-\frac{1}{2}}\left(\delta_{p}(\sigma)-\theta_{0}\right)-\left(1+\frac{\sigma^{2}}{\eta^{2}}\right)^{\frac{1}{2}} \Phi^{-1}(1-\mu)\right)
\end{aligned}
$$


Since $f(\sigma)$ is continuous in an interval around 0 ,

$$
\operatorname{Lim}_{\sigma \rightarrow 0} f(\sigma)=\Phi\left(\operatorname{Lim}_{\sigma \rightarrow 0}\left[\frac{1}{\eta}\left(1+\frac{\eta^{2}}{\sigma^{2}}\right)^{-\frac{1}{2}}\left(\delta_{p}(\sigma)-\theta_{0}\right)-\left(1+\frac{\sigma^{2}}{\eta^{2}}\right)^{\frac{1}{2}} \Phi^{-1}(1-\mu)\right]\right)
$$

Note that $\operatorname{Lim}_{\sigma \rightarrow 0}\left(1+\frac{\sigma^{2}}{\eta^{2}}\right)^{\frac{1}{2}}=1$, and $\operatorname{Lim}_{\sigma \rightarrow 0} \frac{1}{\eta}\left(1+\frac{\eta^{2}}{\sigma^{2}}\right)^{-\frac{1}{2}}=0$. Since $\delta_{p}(\sigma)$ is bounded (by $\underline{\theta}_{i}$ and $\bar{\theta}_{i}$ ), this implies that

$$
\operatorname{Lim}_{\sigma \rightarrow 0} f(\sigma)=\Phi\left(-\Phi^{-1}(1-\mu)\right)=\Phi\left(\Phi^{-1}(\mu)\right)=\mu
$$

Now,

$$
v\left(\delta_{p}\right) \equiv r+e\left[1-2 \Phi\left(\left(\frac{\theta-\widehat{\theta}\left(\theta_{i}=\delta\right)}{\widehat{\eta}}\right)_{\theta=\delta-\sigma \Phi^{-1}(1-\mu)}\right)\right]
$$

Therefore in the limit as $\sigma \rightarrow 0, v\left(\tilde{\delta}_{p}\right)=r+e[1-2 \mu]$, so that

$$
\operatorname{Lim}_{\sigma \rightarrow 0} d=v^{-1}(r)-v^{-1}(r+e[1-2 \mu])
$$

Proof of Proposition 6. The result is implied by Remark 4 (which I state without proof, since this follows immediately), and lemmas 4 and 5

Remark 4 (i) Suppose that for all $i$ in a given set $\Omega_{0}, c_{i}\left(\theta_{i} ; x\right)=0$ for $\Omega=\{i\}$. Then in a equilibrium with no weakly dominated strategies, $c(x)=0$ for $\Omega=\Omega_{0}$; (ii) Suppose that for a given set $\Omega_{0}$, there exists $i \in \Omega_{0}$ such that $c_{i}\left(\theta_{i} ; x\right)=1$ for $\Omega=\{i\}$. Then in a equilibrium with no weakly dominated strategies $c(x)=1$ for $\Omega=\Omega_{0}$

Lemma 4 There exists a $\bar{\eta}$ such that for all $x>q$, whenever $\eta>\bar{\eta}: c(x)=1 \Rightarrow \eta>$ $\bar{\eta}(x)$.

Proof. (1) Let $p_{o v}\left(\theta_{i}\right)$ denote the probability that a PB with ideal point $\theta_{i}$ assigns to the incumbent being overthrown in the event of a challenge. Then $i \in \Omega$ would challenge the incumbent if and only if $p_{o v}\left(\theta_{i}\right) e+u\left(q ; \theta_{i}\right) \geq \max \left\{u\left(x ; \theta_{i}\right)+(e+r) ; u\left(q ; \theta_{i}\right)\right\}$. That is, iff

$$
p_{o v}\left(\theta_{i}\right) \geq \max \left\{\frac{e+r-v_{x}\left(\theta_{i}\right)}{e}, 0\right\}
$$


(2) It is easy to see from here that if $p_{o v}\left(\theta_{i}\right)=1$ for some $i$ (if $i$ believes that if the incumbent is challenged, she will be overthrown), then $i$ would challenge iff $\theta_{i}<v_{x}^{-1}(r){ }^{28}$ It follows from this that there for any belief about the resolution of a challenge $p_{o v}\left(\theta_{i}\right)$ the incumbent will not be challenged provided that $\underline{\omega}=\min \left\{\theta_{i}: i \in \Omega\right\}>v_{x}^{-1}(r)$.

(3) A sufficient condition for a unique voting equilibrium following a challenge is that $e\left|p^{\prime}(\delta)\right|<\left|v^{\prime}(\delta)\right|$ for every $\delta$. Since for every $\delta(i)\left|p^{\prime}(\delta)\right|<\frac{2}{\eta}$ and (ii) $\left|v^{\prime}(\delta)\right|>\underline{\alpha}(x-q)$ (by A1'), this occurs if $2 e / \eta<\underline{\alpha}(x-q)$. Then there will always be a unique equilibrium if

$$
(x-q)<\frac{2 e}{\eta \underline{\alpha}} \Rightarrow \underline{\omega}>v_{x}^{-1}(r)
$$

Note, moreover, that A1' implies that $v_{x}^{-1}(r)<\delta_{0}-\frac{r}{\bar{\alpha}(x-q)}$. Hence (16) becomes:

$$
(x-q)<\frac{2 e}{\eta \underline{\alpha}} \Rightarrow \underline{\omega}>\delta_{0}-\frac{r}{\bar{\alpha}(x-q)}
$$

Writing $\delta_{0}$ as $q+\frac{(x-q)}{2}$, this will always be satisfied provided that:

$$
q+\frac{e}{\eta \underline{\alpha}}-\frac{1}{2} \frac{\alpha}{\bar{\alpha}} \frac{r}{e} \eta<\underline{\omega}
$$

Since the LHS is decreasing in $\eta$ and diverges to $-\infty$ as $\eta \rightarrow \infty$, for any given $\underline{\omega}$ there is an $\bar{\eta}$ such that whenever $\eta>\bar{\eta}$, this inequality is satisfied.

Lemma 5 For $\eta>\bar{\eta}$ there exists a $\widetilde{x}_{\eta} \in R$ such that $c(x)=1 \Leftrightarrow x \geq \widetilde{x}_{\eta}$

Proof. Fix $\eta>\bar{\eta}$. By Lemma $5, c(x)=1 \Rightarrow \eta>\bar{\eta}(x)$. Then for a potential challenger with ideal point $\theta_{i}$, the probability that an active incumbent is overthrown is given by

$$
\operatorname{Pr}\left(\theta<\delta-\sigma \Phi^{-1}(1-\mu) \mid \theta_{i}\right)=\Phi\left(\left(\frac{\theta-\widehat{\theta}\left(\theta_{i}\right)}{\widehat{\eta}}\right)_{\theta=\delta-\sigma \Phi^{-1}(1-\mu)}\right)
$$

Note that $\operatorname{Pr}\left(\theta<\delta-\sigma \Phi^{-1}(1-\mu) \mid \theta_{i}\right)$ is a continuous, decreasing function of $\theta_{i}$, and that $\operatorname{Lim}_{\theta_{i} \rightarrow-\infty} \operatorname{Pr}\left(\theta<\delta-\sigma \Phi^{-1}(1-\mu) \mid \theta_{i}\right)=1$, while $\underset{\theta_{i} \rightarrow \infty}{\operatorname{Lim}} \operatorname{Pr}\left(\theta<\delta-\sigma \Phi^{-1}(1-\mu) \mid \theta_{i}\right)=0$. Then $c_{i}\left(\theta_{i} ; x\right)=1 \Leftrightarrow \theta_{i}<\theta_{c}$, where $\theta_{c}>\underline{\theta_{i}}$, and is uniquely defined by:

$$
r+e P\left(\delta_{p}, \theta_{c}\right) \equiv v_{x}\left(\theta_{c}\right)
$$

\footnotetext{
${ }^{28}$ Suppose that $p_{o v}\left(\theta_{i}\right)=1$ for some $i$ (i.e., $i$ believes that if the incumbent is challenged, she will be overthrown). Then $i$ would challenge iff $\theta_{i}<v_{x}^{-1}(r)$. To see this, note that $e+r-v_{x}\left(\theta_{i}\right)=0$ if $\theta_{i}<v_{x}^{-1}(e+r) \equiv \underline{\theta_{i}}$, while $e+r-v_{x}\left(\theta_{i}\right)>0$, and increases continuously with $\theta_{i}$ for $\theta_{i}>\underline{\theta_{i}}$. Letting $\overline{\bar{\theta}}_{c}$ denote the value of $\theta_{i}$ that solves $1=\max \left\{\frac{e+r-v_{x}\left(\theta_{i}\right)}{e}, 0\right\}$, it follows that (i) a PB would challenge iff $\theta_{i}<\overline{\bar{\theta}}_{c}$, and that (ii) $\overline{\bar{\theta}}_{c}>\underline{\theta_{i}}$, so that $e+r-v_{x}\left(\overline{\bar{\theta}}_{c}\right)>0$ and then $\overline{\bar{\theta}}_{c}=v_{x}^{-1}(r)$.
} 
Note that $\theta_{c}$ so determined is an increasing function of $x, \theta_{c}(x)$. This result can be obtained totally differentiating (17) noting that (1) since the LHS is bounded between $r$ and $r+e, v_{x}\left(\theta_{c}\right)>0$ (every challenger prefers $q$ to $x$ ), (2) whenever $v_{x}\left(\theta_{i}\right)>0$, $v_{x^{\prime}}\left(\theta_{i}\right)>v_{x^{\prime}}\left(\theta_{i}\right)$ for $x \boldsymbol{l}>x$ (for individuals who prefer $q$ to $x$, increasing $x$ increases the payoff of voting for $q$ ), (3) $\delta_{p}$ is increasing in $x$, and therefore $P\left(\delta_{p}, \theta_{c}\right)$ is decreasing in $x$ (since the probability of a succesful challenge increases with $x$ ). Also (4) $P\left(\delta_{p}, \theta_{c}\right)$ is increasing in $\theta_{i}$ and (5) $v_{x}\left(\theta_{i}\right)$ is decreasing in $\theta_{i}$. For a given $x$, there will be a challenge if and only if $\theta_{c}(x) \geq \underline{\omega}$. We know by the previous lemma that if $x<q+\frac{2 e}{\eta \alpha}$, then $c(x)=0$. Thus $\theta_{c}(x)<\underline{\omega}$ for $x<q+\frac{2 e}{\eta \underline{\alpha}}$. Since $\theta_{c}(\cdot)$ is an increasing function of $x$, $c(x)=1 \Leftrightarrow x \geq \widetilde{x}$, where $\widetilde{x}$ is defined by $\theta_{c}(\widetilde{x}) \equiv \underline{\omega}$; i.e., by

$$
r+e P\left(\delta_{p}(\widetilde{x}), \underline{\omega}\right) \equiv v_{\widetilde{x}}(\underline{\omega})
$$




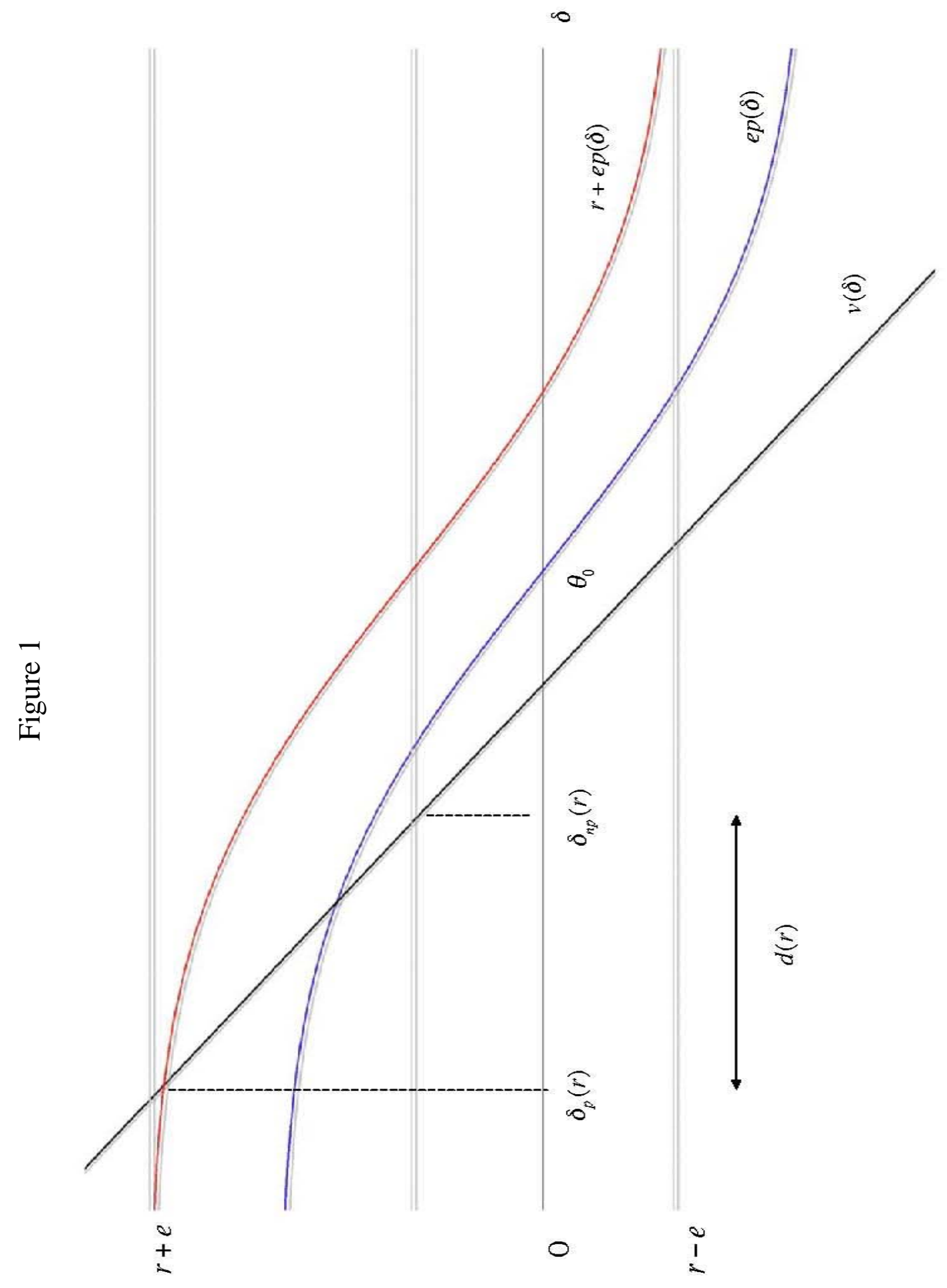




\section{References}

Aldrich, John H. and David W. Rodhe, "The Transition to Republican Rule in the House: Implications for Theories of Congressional Politics," Political Science Quarterly, 1997, 112, 541-567.

_ and _ , "Measuring Conditional Party Government," 1998. Paper presented at the Annual Meeting of the Midwest Political Science Association, Chicago.

Alesina, Alberto and Stephen E. Spear, "An Overlapping Generations Model of Electoral Competition," Journal of Public Economics, December 1988, 37, 359-379.

Angeletos, George-Marios, Christian Hellwig, and Alessandro Pavan, "Learning, Multiplicity and Timing of Attacks in a Dynamic Global Game of Regime Change," March 2006. Department of Economics, University of California at Los Angeles.

Ashworth, Scott and Ethan Bueno de Mesquita, "Informative Party Labels with Institutional and Electoral Variation," 2006. Paper presented at the Annual Meeting of the Midwest Political Science Association, 2004.

Baron, David P., "A Noncooperative Theory of Legislative Coalitions," American Journal of Political Science, November 1989, 33, 1048-1084.

_ and John A. Ferejohn, "Bargaining in Legislatures," American Political Science Review, December 1989, 83, 1181-1206.

Bowler, Shaun, David M. Farrell, and Richard S. Katz, eds, Party Discipline and Parliamentary Government 1999.

Bueno de Mesquita, Bruce, James D. Morrow, Alastair Smith, and Randolph M Siverson, "Policy Failure and Political Survival," Journal of Conflict Resolution, April 1999, 43, 147-161.

_ , _ , , and _ , "Political Institutions, Policy Choice and the Survival of Leaders," British Journal of Political Science, 2002, 32, 559-590.

_ , _, , and _, The Logic of Political Survival, Cambridge: MIT Press, 2003.

Caillaud, Bernard and Jean Tirole, "Parties as Political Intermediaries," Quarterly Journal of Economics, November 2002, 117, 1453-1489.

Calvert, Randall, "Reputation and Legislative Leadership," Public Choice, September 1987, 55, 81-119.

- and Justin Fox, "Effective Parties in a Model of Repeated Legislative Bargaining," 2003. Department of Political Science, Washington University at Saint Louis.

- and Nathan Dietz, "Legislative Coalitions in a Bargaining Model with Externalities," July 1998. Working Paper 16, Wallis Institute of Political Economy, University of Rochester. 
Cox, Gary and Keith Poole, "On Measuring Partisanship in Roll Call Voting: The U.S. House of Representatives, 1877-1999," 2002. Unpublished Article. University of California at San Diego.

- and Mathew McCubbins, Legislative Leviatan. Party Government in the House, CA: University of California Press, 1993.

_ and _ , "A Precis on Legislative Leadership," 2005. Department of Political Science, University of California, San Diego.

_ and _, Setting the Agenda. Responsible Party Government in the U.S. House of Representatives, Cambridge: Cambridge University Press, 2005.

Dekel, Eddie, Matthew O. Jackson, and Asher Wolinsky, "Vote Buying," 2004. Working Paper, California Institute of Technology.

Diermeier, Daniel and Roger Myerson, "Bicameralism and its Conssequences for the Internal Organization of Legislatures," American Economic Review, December 1999, 89, 1182-1196.

- and Timothy Feddersen, "Cohesion in Legislatures and the Vote of Confidence Procedure," American Political Science Review, September 1998, 92, 611-621.

Frankel, David, Stephen Morris, and Ady Pauzner, "Equilibrium Selection in Global Games with Strategic Complementarities," Journal of Economic Theory, 2001, $108,1-44$.

Groseclose, Tim and James M. Snyder, "Buying Supermajorities," American Political Science Review, June 1996, 90, 303-315.

Huber, John D., "The Vote of Confidence in Parliamentary Democracies," American Political Science Review, June 1996, 90, 269-282.

Jackson, Matthew O. and Boaz Moselle, "Coalition and Party Formation in a Legislative Voting Game," Journal of Economic Theory, 2002, 103, 49-87.

Jones, Charles O., "Joseph G. Canon and Howard W. Smith: An Essay on the Limits of Leadership in the House of Representatives," Journal of Politics, 1968, 30, 617-646.

Kiewit, Roderick and Matthew McCubbins, The Logic of Delegation. Congressional Parties and the Appropriations Process, IL: The University of Chicago Press, 1991.

Krehbiel, Keith, "Where's the Party?," British Journal of Political Science, 1993, 23, 235-266.

Laver, Michael and Kenneth A. Shepsle, "Government Coalitions and Intraparty Politics," British Journal of Political Science, October 1990, 20, 489-507. 
Levy, Gilat, "A Model of Political Parties," Journal of Economic Theory, 2004, 115, 250-277.

Lizzeri, Alessandro and Nicola Persico, "The Provision of Public Goods under Alternative Electoral Incentives," American Economic Review, 2001, 91, 225-239.

Mattozzi, Andrea and Antonio Merlo, "Political Careers or Careers Politicians," December 2005. PIER Working Paper 05-032, University of Pennsylvania.

McCarty, Nolan, Keith T. Poole, and Howard Rosenthal, "The Hunt for Party Discipline in Congress," American Political Science Review, September 2001, 95, 673687.

McKenzie, R.T., British Political Parties, New York: Frederick A. Prraeger, Publisher, 1964.

Merlo, Antonio, "Wither Political Economy? Theories, Facts and Issues," December 2005. Department of Economics, University of Pennsylvania.

Michels, Robert, Political parties; A Sociological Study of the Oligarchical Tendencies of Modern Democracy. Translated by Eden and Cedar Paul (first published 1911), NY: Collier Books, 1962.

Morelli, Massimo, "Party Formation and Policy Outcomes under Different Electoral Systems," Review of Economic Studies, 2004, 71, 829-853.

Morgenstern, Scott, Patters of Legislative Politics. Roll-Call Voting in Latin America and the United States, Cambridge: Cambridge University Press, 2004.

_ and Benito Nacif, eds, Legislative Politics in Latin America 2002.

Morris, Stephen and Hyun Song Shin, "Unique Equilibrium in a Model of SelfFulfilling Currency Attacks," American Economic Review, 1998, 88, 587-597.

_ and _ , "Global Games: Theory and Applications ," 2001. Cowles Foundation Discussion Paper No. 1275R, Cowles Foundation for Research in Economics, Yale University.

_ and _, "Heterogeneity and Uniqueness in Interaction Games," 2003. Cowles Foundation Discussion Paper No. 1402, Cowles Foundation for Research in Economics, Yale University.

Myerson, Roger B., "Incentives to Cultivate Favored Minorities Under Alternative Electoral Systems," American Political Science Review, December 1993, 87, 856-869.

_ , "Leadership, Trust, and Constitutions," October 2005. Department of Economics, University of Chigago.

Osborne, Martin J. and Rabee Tourky, "Party Formation in Single-Issue Politics," July 2004. Department of Economics, University of Toronto. 
Panebianco, Angelo, Political Parties: Organization and Power, Cambdridge: Cambridge University Press, 1988.

Roemer, John, "The Democratic Political Economy of Progressive Taxation," Econometrica, 1999, 67, 1-19.

Sinclair, Barbara, Majority Leadership in the House, Baltimore: The Johns Hopkins University Press, 1983.

Snyder, James M., "On Buying Legislatures," Economics and Politics, 1991, 3, 93-109.

- and Michael M. Ting, "An Informational Rationale for Political Parties," American Journal of Political Science, January 2002, 46, 90-110.

- and Tim Groseclose, "Estimating Party Influence in Congressional Roll-Call Voting," American Journal of Political Science, April 2000, 44, 193-211.

Tsebelis, George, "Decision Making in Political Systems: Veto Players in Presidentialism, Parlamentarism, Multicameralism, and Multipartyism," British Journal of Political Science, July 1995, 25, 289-325. 